\title{
LARGE-SCALE SECRETOME ANALYSES UNVEIL THE SUPERIOR IMMUNOSUPPRESSIVE PHENOTYPE OF UMBILICAL CORD STROMAL CELLS AS COMPARED TO OTHER ADULT MESENCHYMAL STROMAL CELLS
}

\author{
A. Islam ${ }^{1}$, I. Urbarova ${ }^{2}$, J.A. Bruun ${ }^{2}$ and I. Martinez-Zubiaurre ${ }^{1, *}$ \\ ${ }^{1}$ Department of Clinical Medicine, UiT The Arctic University of Norway, Tromsø, Norway \\ ${ }^{2}$ Tromsø University Proteomics Platform, Department of Medical Biology, UiT \\ The Arctic University of Norway, Tromsø, Norway
}

\begin{abstract}
Mesenchymal stromal cells (MSCs), given their regenerative potential, are being investigated as a potential therapeutic tool for cartilage lesions. MSCs express several bioactive molecules which act in a paracrine fashion to modulate the tissue microenvironment. Yet, little is known about the divergence of these signalling molecules in different MSC populations. The present study investigated secretomes of stromal cells harvested from Hoffa's fat pad (HFPSCs), synovial membrane (SMSCs), umbilical cord (UCSCs) and cartilage (ACs) by quantitative liquid chromatography-mass spectrometry (LC-MS/MS) proteomics. Also, multiplex protein arrays and functional assays were performed to compare the constitutive immunomodulatory capabilities of different MSCs. Proteins involved in extracellular matrix degradation and inflammation, such as matrix metalloproteinases (MMPs), interleukin (IL)-17 and complement factors, were downregulated in UCSCs as compared to adult cell sources. Additionally, secretion of transforming growth factor (TGF)- $\beta 1$ and prostaglandin E2 (PGE2) was enhanced in UCSC supernatants. UCSCs were superior in inhibiting peripheral blood mononuclear cell (PBMC) proliferation, migration and cytokine secretion as compared to adult stromal cells. SMSCs significantly suppressed the proliferation of PBMCs only if they were primed with pro-inflammatory cytokines. Although all cell types repressed human leukocyte antigen-DR isotype (HLADR) surface expression and cytokine release by activated macrophages, only UCSCs significantly blocked IL-6 and IL-12 production. Furthermore, UCSCs supernatants increased aggrecan gene expression in twodimensional chondrocyte cultures. The data demonstrated that UCSCs displayed superior anti-inflammatory and immunosuppressive properties than stromal cells from adult tissues. This allogeneic cell source could potentially be considered as an adjuvant therapy for articular cartilage repair.
\end{abstract}

Keywords: Secretome, umbilical cord stromal cells, chondrocytes, Hoffa's fat pad-derived stromal cells, synovial membrane stromal cells, mesenchymal stromal cells, immunomodulation, cartilage repair.

*Address for correspondence: Prof. Inigo Martinez-Zubiaurre, Department of Clinical Medicine, UiT The Arctic University of Norway, 9037 Tromsø, Norway.

Telephone number:+4777644686Ｅmail: inigo.martinez@uit.no

Copyright policy: This article is distributed in accordance with Creative Commons Attribution Licence (http://creativecommons.org/licenses/by-sa/4.0/).

\section{Introduction}

Articular cartilage lesions associate with pain, discomfort and inflammation of the synovial joint, which subsequently restrict the function of the joint. Mechanical trauma or degenerative disorders are the major causes of articular cartilage injuries (Chubinskaya et al., 2015). Traumatic cartilage lesions may increase the risk of developing osteoarthritis (OA) by more than four times (Muthuri et al., 2011).
This fast-growing chronic disease is expected to be the fourth leading cause of disability by 2020 (Cross et al., 2014). Commonly used surgical and nonsurgical OA treatment modalities include intraarticular injections of soluble materials, such as corticosteroids or hyaluronate, autologous blood products, nonsteroidal anti-inflammatory drugs (NSAIDs) and arthroscopic lavage. These procedures improve OA symptoms to a certain degree but do not heal completely the progressive loss of joint 
functions (Lee and Wang, 2017; Wolfstadt et al., 2015). Additionally, the treatment of localised cartilage injuries with cell-based therapies benefits patients with debilitative knee functions and delays the onset of secondary OA (Ogura et al., 2017). Although autologous chondrocytes are used as an intuitive source for cell-based therapy (Knutsen et al., 2016; Saris et al., 2014), in recent years, mesenchymal stromal cells (MSCs) are gaining attention as an alternative and potentially effective therapeutic tool for cartilage lesions.

MSCs are successfully isolated and expanded in vitro from numerous tissues sources. MSCs represent a defined population of multipotent progenitor cells residing in the perivascular niche of nearly all human tissues, although different views exist (Crisan et al., 2008; Guimaraes-Camboa et al., 2017). MSC differentiation capacity and immunomodulatory properties are demonstrated in vitro, irrespective of tissue sources (Ghannam et al., 2010). However, in vitro studies show that MSCs from different origins differ in their lineage-specific differentiation capacity and their functional potential (Garcia et al., 2016; Islam et al., 2016; Subramanian et al., 2015). In addition, a systematic review of intra-articular injection of bone marrow MSCs in humans has concluded that articular stem cell therapies are safe (Peeters et al., 2013). Some preclinical studies in animals demonstrate the in vivo efficacy of MSCs from different sources, including autogenic, allogeneic and xenogeneic, in OA management. However, none of these studies has compared the optimal source of MSCs (Ozeki et al., 2016; Saulnier et al., 2015; Singh et al., 2014; Yang et al., 2015). Therefore, the choice of optimal MSC source for a given clinical implication has yet to be elucidated.

In mechanistic terms, it is not well established how MSCs exert their effects in vivo. Liechty et al. (2000) propose that MSCs promote tissue regeneration by engraftment of cells in damaged areas and transdifferentiation into tissue-forming cells to promote repair. Recently, paracrine signalling and release of potent bioactive factors have emerged as modulators of the microenvironment during tissue healing (Gnecchi et al., 2016; Iso et al., 2007; Prockop, 2009). In the field of cartilage repair and OA, the fate of implanted cells during biological repair procedures and their contribution to rebuilding the damaged tissue is mostly unknown. Previous studies in animals suggest that most of the repaired tissue is composed of cells of unknown origin migrating to the lesion (Dell'Accio et al., 2003; Grande et al., 1989). A recent human clinical trial has concluded that allogeneic bone marrow MSCs function as a source of stimulatory and trophic factors, which orchestrate tissue repair rather than differentiating into the host tissue (de Windt et al., 2017).

Clinical procedures based on autologous MSC transplantation, including bone marrow or adipose tissue MSCs, may provide beneficial effects, but are associated with invasive harvesting procedures, two- stage operations and long-time cell expansion ex vivo. Allogeneic MSCs harvested from umbilical cords, amniotic membrane and placenta might represent alternative sources for one-stage cell-based therapies. In addition to their pro-angiogenic properties, anti-inflammatory phenotype and multi-lineage differentiation potential, these allogeneic MSCs are well tolerated and elicit low immunogenic responses as their adult counterparts (Balasubramanian et al., 2012; Donders et al., 2015). Differently from the investigation into the neo-tissue-forming ability, the role of secreted bioactive molecules in the context of paracrine signalling and immunomodulation have not been comprehensively explored between cells from adult joints and young cells. The aim of the present study was to find the most suitable cell source to promote immunomodulation and chondrogenesis from the paracrine signalling perspective. The number of published studies presenting comparative analyses of secretory profiles between different cell types is very limited (Amable et al., 2014; Dabrowski et al.., 2017). Among those, the present study was the only one applying both large-scale secretomics and multiplex protein analyses and integrating functional immune assays to validate the results.

The present study compared the secretome of culture-expanded cells harvested from four different tissues sources comprising articular cartilage (ACs), Hoffa's fat pad stromal cells (HFPSCs), synovial membrane stromal cells (SMSCs) and umbilical cords stromal cells (UCSCs). For analyses, mechanisms and pathways relevant to cartilage and joint physiology, including inflammation and

Table 1. Demographics of patients from which cells were isolated. M: male; F: female; ICRS: International Celestial Reference System (van den Borne et al., 2007).

\begin{tabular}{|c|c|c|c|}
\hline Donor & Gender & $\begin{array}{c}\text { Age } \\
\text { (years) }\end{array}$ & $\begin{array}{c}\text { ICRS } \\
\text { grade }\end{array}$ \\
\hline 1 & M & 40 & I/II \\
\hline 2 & F & 46 & II/III \\
\hline 3 & M & 47 & II/III \\
\hline 4 & F & 54 & II \\
\hline 5 & F & 60 & III \\
\hline 6 & M & 60 & II \\
\hline 7 & M & 61 & III \\
\hline 8 & F & 67 & III \\
\hline 9 & F & 70 & II \\
\hline 10 & F & 70 & III \\
\hline 11 & F & 71 & II/III \\
\hline 12 & M & 73 & III \\
\hline 13 & M & 74 & III \\
\hline 14 & M & 76 & II/III \\
\hline 15 & M & 77 & III \\
\hline
\end{tabular}


immune regulation, extracellular matrix (ECM) remodelling, mitotic factors and chondro-inductive molecules, were considered. Proteins involved in ECM remodelling, such as matrix metalloproteinases (MMPs), complement factors and serpins, were significantly downregulated in UCSCs as compared to other cell types, whereas cell signalling molecules, such as transforming growth factor (TGF)- $\beta 1$, monocyte chemoattractant protein-1 (MCP-1) and platelet derived growth factor D (PDGFD), were upregulated in UCSCs. Additionally, the effects of cell supernatants on cartilage signature genes expression in two-dimensional (2D) chondrocyte culture were investigated. UCSCs significantly enhanced the expression of aggrecan gene by dedifferentiated chondrocytes. To evaluate the constitutive abilities of the different MSCs as immunomodulators, the immunoregulatory properties of supernatants from the different cell types were compared by functional immune assays. Data revealed that UCSCs exhibited superior anti-inflammatory properties and low catabolic phenotypes as compared to ACs, HFPSCs and SMSCs.

\section{Materials and Methods}

\section{Human materials and ethical statements}

Human samples were collected from the University Hospital of Northern Norway (UNN). The Regional Ethical Committee (REK Nord 2014/920 and 2010/586) at the University of Tromsø approved the study. Adult stromal cells were isolated from knee joint tissues of 15 patients (40-77 years old) undergoing total knee replacement (TKR). Patients' demographics are summarised in Table 1. A macroscopic observation was made by the operating surgeon to assess the inflammatory state of the sample. Patients with inflammatory joint diseases and very advanced OA were excluded; however, both secondary post-traumatic and primary OA patients were included in the study. Fat pad and synovial membrane tissues were harvested from TKR patients. UCSCs were isolated from seven umbilical cords immediately after birth. Buffy-coats for isolation of peripheral blood mononuclear cells (PBMCs) were collected from healthy donors from the local blood bank (REK Nord 2014/401). All patients provided written informed consent.

\section{Isolation and culture of human stromal cells} Macroscopically-normal-looking cartilage, corresponding to cartilage areas looking intact to the eye and presenting no signs of abnormalities, such as tears, scratches, rugose or eroded tissue, was collected from femoral condyles during total knee replacements and was used to isolate human chondrocytes. All cell types were isolated using a mixed enzymatic-explant method, as previously described (Islam et al., 2016; Islam et al., 2017). Briefly, all tissue specimens were washed three times with sterile Dulbecco's phosphate buffered saline (PBS; D8537, Sigma-Aldrich) and minced into small pieces for subsequent enzymatic digestion in collagenase XI solution ( $\geq 800$ units/mg solid; C9407, Sigma-Aldrich) at a final concentration of $1.25 \mathrm{mg} / \mathrm{mL}$ at $37^{\circ} \mathrm{C}$ on a shaker at $400 \mathrm{rpm}$. Cartilage tissue specimens were digested for 3-4 $\mathrm{h}$, other adult tissue specimens were digested only for 1-1.5 h. UCSCs were isolated from $40 \mathrm{~mm}$-long cord fragments (also known as mixed cords) previously sterilised by immersion in $90 \%$ ethanol for $30 \mathrm{~s}$ and enzymatically digested for $1 \mathrm{~h}$ collagenase XI. Partially digested tissues were centrifuged for $10 \mathrm{~min}$ at $800 \times g$ and resuspended in high-glucose Dulbecco's modified Eagle medium (DMEM; D5796; Sigma-Aldrich) before plating in a T-75 culture flask (156499; ThermoFisher Scientific). The culture medium was supplemented with $62 \mathrm{mg} / \mathrm{L}$ L-ascorbic acid (103033E, BDH Laboratory, Pole, UK), $1 \%$ penicillin and streptomycin (P/S; P4333, SigmaAldrich) and $20 \%$ foetal bovine serum (FBS; S0115, Biochrom) to promote cell attachment. All cells were incubated in a humidified atmosphere containing $5 \% \mathrm{CO}_{2}$ at $37{ }^{\circ} \mathrm{C}$. After the initial $24 \mathrm{~h}$, primary cultures were expanded in $10 \%$ FBS-supplemented medium and the medium was changed every 3-4 $\mathrm{d}$ until the cultures became confluent. Cells from all tissue sources were used for experiments at passage (P) 3 and 4 .

\section{Preparation of conditioned medium (CM)}

Serum-containing CM was used in the functional assays with PBMCs and macrophages, whereas serum-free CM was used for protein-arrays and secretomics. Upon reaching 70-80\% confluence, culture flasks were thoroughly washed with warm PBS and the medium was replaced with fresh highglucose DMEM containing $1 \% \mathrm{P} / \mathrm{S}$, with or without $10 \%$ FBS. Serum-free medium was supplemented with $1 \mu \mathrm{g} / \mathrm{mL}$ dexamethasone (PZN-3103491; Galenpharma, Kiel, Germany) and $1: 1000$ insulintransferrin-selenium supplement (ITS; 354351; Corning). For priming of cells with pro-inflammatory cytokines, growth media were supplemented for $48 \mathrm{~h}$ with $50 \mathrm{ng} / \mathrm{mL}$ each of tumour necrosis factor alpha (TNF- $\alpha ; 300-01 \mathrm{~A}$, PeproTech) and interferon gamma (IFN $\gamma ; 300-02$, PeproTech). CM was collected after $48 \mathrm{~h}$, centrifuged at $4500 \times g$ for $10 \mathrm{~min}$, filtered through a $0.22 \mu \mathrm{m}$ porous membrane (GSWP04700; Millipore) and used immediately for experiments or stored at $-70^{\circ} \mathrm{C}$ for further analysis. Cells were counted for each culture condition and the value used to normalise the measured expression of cytokines and growth factors in the CM. In functional assays with PBMCs and macrophages, the fresh culture medium was diluted with serum-containing $\mathrm{CM}$ $(1: 1)$ from different stromal cells.

\section{Quantitative and qualitative liquid chromatography-} mass spectrometry (LC-MS/MS) analysis

$6 \mathrm{~mL}$ of serum-free $\mathrm{CM}$ from all cultures were collected from T-75 culture flasks and concentrated 
for $20 \mathrm{~min}$ at $4500 \times g$ in PBS to a final volume of 500-800 $\mu \mathrm{L}$ using a $5 \mathrm{kDa}$ molecular weight cut-off (MWCO) Vivaspin 6 column (Z614440-25EA, SigmaAldrich). Protein concentration was measured using DC Protein Assay Kit (5000116, Bio-Rad). Protein samples were prepared as described before (Islam et al., 2019). Briefly, protein samples $(100 \mu \mathrm{g} / \mathrm{tube})$ were reduced in $5 \mathrm{mM}$ dithiothreitol (D9779, SigmaAldrich) for $30 \mathrm{~min}$ at $70{ }^{\circ} \mathrm{C}$. Samples were alkylated by incubation with $375 \mathrm{mM}$ iodoacetamide (90034, ThermoFisher Scientific) at room temperature for $30 \mathrm{~min}$ in the dark. Protein samples were collected as dry pellets after overnight precipitation in prechilled acetone (270725, Sigma-Aldrich) at $-20{ }^{\circ} \mathrm{C}$. Dry pellets containing $100 \mu \mathrm{g}$ of protein were resuspended in $100 \mu \mathrm{L}$ of $2 \mathrm{M}$ urea (U1250, SigmaAldrich) with $50 \mathrm{mM}$ triethylammonium bicarbonate (TEAB; 90114, ThermoFisher Scientific). Only 25 ug of protein per sample were taken for further analysis. Samples were pre-digested for $6 \mathrm{~h}$ with $1: 100(\mathrm{w} / \mathrm{w})$ LysC endopeptidase (125-05061, Wako Chemicals, Neuss, Germany) with $1 \mathrm{mM}$ final concentration of $\mathrm{CaCl}_{2}$, followed by further dilution with $50 \mathrm{mM}$ TEAB in $1 \mathrm{M}$ urea and digestion overnight in $1: 20$ (w/w) trypsin (V511A, Promega). $5 \mu$ L trifluoroacetic acid (10\%) (28904, ThermoFisher Scientific) were added to each tube and centrifuged at $16,000 \times g$ for $10 \mathrm{~min}$. OMIX C18 tips were used for sample cleanup and concentration. Samples containing $0.2 \%$ formic acid (FA; 28905, ThermoFisher Scientific) were loaded into a ThermoFisher Scientific EASYnLC1000 system and EASY-Spray column (C18, $2 \mu \mathrm{m}, 10 \mathrm{~nm}, 50 \mu \mathrm{m}, 500 \mathrm{~mm})$. Peptides were fractionated using a 2-100\% acetonitrile (51101, ThermoFisher Scientific) gradient in $0.1 \%$ FA at a flow rate of $250 \mathrm{~nL} / \mathrm{min}$ over $180 \mathrm{~min}$. The separated peptides were analysed using a ThermoFisher Scientific Q-Exactive mass spectrometer. Data were collected by Top10 method in data-dependent mode. The raw data were processed using MaxQuant (v 1.5.6.0) for label-free protein quantification (LFQ). MS/MS data were searched against the UniProt human database (Web ref. 1) from November 2016 to yield protein identification [false discovery rate $(F D R)=0.01]$. Parameters used for the search: fixed modification, carbamidomethylation of cysteines; variable modifications, oxidation of methionine and acetylation of protein N-terminal; ion mass tolerance, 4.5 ppm; fragment mass tolerance, 20 ppm; charge states, 2+, 3+ and 4+; maximum missed cleavages, 2; enzyme specificity, trypsin; minimum number of unique peptides, 2. Perseus 1.5.6.0 software (Max Planck Institute of Biochemistry, Germany) was used for statistical analysis of the identified proteins. All contaminants were filtered out before $\log _{10}$-transformation of data for further analysis. The $\log _{10}$-transformed intensities were normalised by subtracting the median. Data were grouped as ACs, HFPSCs, SMSCs and UCSCs and analysed using a $t$-test, with a minimum of three valid values in each group. Volcano plots for each comparison were generated to identify differentially expressed proteins using FDR $<0.01$.

\section{Multiplex protein arrays}

A panel of 36 specific proteins including cytokines, chemokines, MMPs and growth factors was measured in the serum-free CM of all four stromal cell types by immune-based protein array. A human cytokine magnetic 25-plex kit (LHC0009M, ThermoFisher Scientific) was used to measure the concentration of 18 cytokines ( $1: 4$ dilution) involved in inflammation - including granulocyte-macrophage colony-stimulating factor (GM-CSF), IFN- $\alpha$, IFN- $\gamma$, interleukin (IL)-1 $\beta$, IL-1RA, IL-2, IL-2R, IL-4, IL-5, IL-6, IL-7, IL-8, IL-10, IL-12 (p40/p70), IL-13, IL-15, IL-17 and TNF- $\alpha$ - and 7 chemokines (1:4 dilution) including eotaxin, interferon-gamma-induced protein 10 (IP-10), MCP-1, MIG, macrophage inflammatory proteins (MIP)-1 $\alpha$, MIP-1 $\beta$ and RANTES. Fluorokine MAP human MMP base kit (LMP000, R\&D Systems) was used to measure the concentration of MMP-1, MMP-3, MMP-7, MMP-9 and MMP-13 (1: 5 dilution). Quantitative measurements (two replicates) were performed according to manufacturers' guidelines using Luminex Bio-Plex 200 system (Bio-Rad). In addition, quantification of PGE2 (KGE004B), IL-4 (DY204-05), IL-10 (DY217B-05) and the five growth factors TGF- $\beta 1$ (DY240-05), BMP-2 (DY355-05), IGF-1 (DY291-05), PDGF-AB (DY222) and basic fibroblast growth factor (bFGF) (DY233-05) was performed by enzyme-linked immunosorbent assay (ELISA). All ELISA kits were purchased from R\&D Systems and performed according to the manufacturer' instructions. Measured protein concentrations were normalised to cell number at specific culture conditions and expressed as $\mathrm{pg} / \mathrm{mL} / 10^{6}$ cells.

\section{Isolation and culture of human PBMCs}

PBMCs were isolated from buffy-coats $(n=5)$ of whole blood using Lymphoprep ${ }^{\mathrm{TM}}$ (1114545, Alere Technologies, Oslo, Norway) following the manufacturer' instructions. Briefly, peripheral blood was diluted in sterile PBS (1:1) and slowly layered over a Lymphoprep ${ }^{\mathrm{TM}}$ gradient in a $50 \mathrm{~mL}$ tube. The tube was centrifuged at $800 \times g$ for $30 \mathrm{~min}$ at room temperature. PBMCs were collected from the gradient-interface with a Pasteur pipette, followed by washing three times for $10 \mathrm{~min}$ at $400 \times g$ with phosphate $\mathrm{NaCl}$ (PBSA) containing PBS and $0.2 \%$ bovine serum albumin (BSA; 130-091-376, Miltenyi Biotec). PBMCs were cultured in growth medium containing Rosewell Park Memorial Institute medium (RPMI-1640; R8758, Sigma-Aldrich), $1 \%$ P/S and $10 \%$ FBS in a humidified atmosphere $\left(5 \% \mathrm{CO}_{2}\right)$ at $37^{\circ} \mathrm{C}$.

\section{PBMC proliferation assay}

PBMC proliferation was assessed using the carboxyfluorescein succinimidyl ester (CFSE) dilution assay (10009853, Cayman). Cultured PBMCs were washed in pre-warmed sterile PBS and centrifuged at $400 \times g$ for 5 min before incubation with 
CFSE for $15 \mathrm{~min}$ at $1: 400$ dilution. CFSE-stained PBMCs were cultured in RPMI, $1 \% \mathrm{P} / \mathrm{S}$ and $10 \%$ FBS in a 24-well plate at a density of $10^{6}$ cells/well. PBMCs were stimulated with $10 \mu \mathrm{g} / \mathrm{mL}$ mitogen phytohemagglutinin (PHA; 1249738, Roche) for $5 \mathrm{~d}$ to induce proliferation. Half of the medium was replaced with fresh medium after the second day. The proliferation assay was performed on a BD FACSAria III flow cytometer (BD Biosciences) and the data were analysed by FlowJo software (Tree Star Inc., Ashland, OR, USA). CM from stromal cells was added to the culture of PHA-activated PBMCs from day 1 at $1: 1$ ratio with fresh culture medium. $\mathrm{CM}$ from the last $3 \mathrm{~d}$ of PBMC proliferation was collected to measure cytokine profiles. CM derived from PBMCs was centrifuged at $4500 \times g$ for $5 \mathrm{~min}$ and filtered through a $0.22 \mu \mathrm{m}$ porous membrane (GSWP04700; Millipore) before analysing TNF- $\alpha$ (DY210-05; R\&D Systems) and IFN- $\gamma$ (DY285-05; R\&D Systems) content by ELISA.

\section{PBMC migration assay}

PBMC migration assay was performed by Boyden chamber assay (Gorchs et al., 2015). PBMCs were activated with $10 \mu \mathrm{g} / \mathrm{mL}$ PHA for $48 \mathrm{~h}$ before performing the assay. $100 \mathrm{ng} / \mathrm{mL}$ recombinant stromal cell-derived factor-1 (SDF-1;300-28A, PeproTech) was used as a chemoattractant. $10^{6}$ cells $/ 100 \mu \mathrm{L}$ PBMCs were added to the top chamber of Corning ${ }^{\circledR}$ Costar $^{\circledR}$ Transwell ${ }^{\circledR}$ cell culture inserts $(6.5 \mathrm{~mm}$ diameter, 8 um pores; CLS3464-48EA, Sigma-Aldrich). Bottom chambers contained either growth medium or serumrich CM from different stromal cells. After $2 \mathrm{~h}, \mathrm{PBMCs}$ that migrated to the lower chamber were harvested and washed in PBSA by centrifugation at $400 \times g$ for $4 \mathrm{~min}$ followed by resuspension in $0.5 \mathrm{~mL}$ of PBSA. Lymphocytes population was gated using forward and side scatter and counted on a BD FACSAria III flow cytometer.

\section{Isolation and culture of monocyte-derived macrophages}

Monocytes were isolated from PBMCs using CD14 ${ }^{+}$ magnetic-activated cell sorting (MACS; 130-050201, Miltenyi Biotec) with minor modification from manufacturer' guidelines. Briefly, PBMCs were washed in MACS buffer containing autoMACS rinsing solution (130-091-222, Miltenyi Biotec) and BSA $(20: 1)$ for $10 \mathrm{~min}$ at $4{ }^{\circ} \mathrm{C}$. PBMCs were incubated with $\mathrm{CD} 14^{+}$microbeads at a concentration of $10 \mu \mathrm{L}$ beads $/ 10^{7}$ cells in $40 \mu \mathrm{L}$ of MACS buffer for $15 \mathrm{~min}$ at $4{ }^{\circ} \mathrm{C}$. PBMCs were rinsed in MACS buffer and resuspended in an appropriate volume before passing through the MS column. CD14 ${ }^{+}$ monocytes were eluted from the column and washed with ice-cold MACS buffer. The purity of eluted monocytes was checked by flow cytometry using anti-CD14-fluorescein isothiocyanate (FITC)conjugated antibody (130-098-063, Miltenyi Biotec) and its isotype control mouse IgG2a-FITC (130-098877). Fully transformed macrophages (M0-M) were achieved after $6 \mathrm{~d}$ incubation of $\mathrm{CD} 14^{+}$monocytes in a macrophage growing medium containing RPMI1640, 1 \% P/S, 10 \% FBS and 100 ng/mL macrophage colony-stimulating factor (M-CSF; 300-25, PeproTech) in a humidified atmosphere $\left(5 \% \mathrm{CO}_{2}\right)$ at $37^{\circ} \mathrm{C}$. The medium was replaced with fresh medium after $3 \mathrm{~d}$.

\section{Macrophage polarisation assay}

For induction of the M1 phenotype (M1-M), M0-M were plated in a 6-well plate at a density of $2.5 \times 10^{6}$ cells/well and stimulated for $48 \mathrm{~h}$ with $100 \mathrm{ng} / \mathrm{mL}$ lipopolysaccharides (LPS; L6529-1MG, Sigma-Aldrich) and $20 \mathrm{ng} / \mathrm{mL}$ IFN- $\gamma$. To investigate the effects of cell secretomes on M1-M polarisation, macrophage culture medium was diluted with serum-rich CM $(1: 1)$ from different stromal cells. Macrophages were harvested after $48 \mathrm{~h}$ and washed in MACS buffer before analysing on BD FACSAria III flow cytometer. FlowJo software was used for analysing surface markers expression.

M1-M polarisation was characterised by surface marker expression of CD40 (130-099-385, Miltenyi Biotec), CD64 (130-100-415, Miltenyi Biotec), CD80 (130-110-371, Miltenyi Biotec), CD86 (560957; BD Biosciences) and HLA-DR (560943, BD Biosciences). All antibodies were phycoerythrin (PE)-conjugated and analysed with respective isotype controls, including mouse IgG1 (130-098-845, Miltenyi Biotec), REA control (130-104-612, Miltenyi Biotec) and mouse IgG2a (555574, BD Biosciences). For induction of M2 phenotype (M2-M), M0-M were stimulated with $4 \mu \mathrm{g} / \mathrm{mL}$ dexamethasone for $48 \mathrm{~h}$ and characterised by surface marker expression of

Table 2. qPCR probes.

\begin{tabular}{|c|c|c|}
\hline Gene name & Gene symbol & Assay ID \\
\hline Collagen type I $\alpha 1$ & COL1A1 & Hs00164004_m1 \\
\hline Collagen type II $\alpha 1$ & COL2A1 & Hs00264051_m1 \\
\hline Aggrecan & ACAN & Hs00153936_m1 \\
\hline sex determining region Y (SRY)-box 9 & SOX9 & Hs00165814_m1 \\
\hline Ribosomal protein L13A & RPL13A & Hs04194366_g1 \\
\hline
\end{tabular}


CD163-FITC; 130-099-969, Miltenyi Biotec) and its isotype control mouse IgG1-FITC (130-098-847). To further investigate the effects of $\mathrm{CM}$ from all cell types on M1-M polarisation, macrophage-CM was collected after $48 \mathrm{~h}$, centrifuged at $4500 \times g$ for $5 \mathrm{~min}$, filtered by $0.22 \mu \mathrm{m}$ porous membrane (GSWP04700; Millipore) and used immediately for experiments or stored at $-70{ }^{\circ} \mathrm{C}$ for further analysis. The concentration of TNF- $\alpha$, IL-6 (DY206-05) and IL-12 (DY1240-05) were measured by ELISA. All ELISA kits were purchased from R\&D Systems.

\section{qPCR}

Dedifferentiated chondrocytes at P3 were cultured for $48 \mathrm{~h}$ in the presence of stimulated and non-stimulated CM. After $48 \mathrm{~h}$, chondrocytes were harvested for qPCR to analyse the expression of cartilage signature genes. Dedifferentiated chondrocytes at P2 and P3 grown in the absence of $\mathrm{CM}$ were used as controls. The $\mathrm{qPCR}$ reaction was performed as described before (Hansen et al., 2017). Briefly, RNA was extracted according to the manufacturer's guidelines using the RNeasy Plus Mini Kit (74134, QIAGEN). Each RNA template was reverse transcribed to cDNA using the qScript cDNA Synthesis Kit (95047, Quanta Biosciences). The qPCR reaction was run on a StepOnePlus ${ }^{\mathrm{TM}}$ Real-Time PCR system (Applied Biosystems). Probes used are summarised in Table 2. Gene relative expression was presented using the $\Delta \mathrm{Cq}$ value (Hansen et al., 2017) and calculated by subtracting the gene of interest from the reference gene (RPL13A), making higher $\Delta \mathrm{Cq}$ value represents increased gene expression and vice versa.

\section{Three-dimensional (3D) cultures}

In vitro $3 \mathrm{D}$ chondrogenic assays of dedifferentiated chondrocytes was performed using a pellet culture method as described previously (Islam et al., 2016). Briefly, chondrocytes were harvested at P3, centrifuged in a conical-bottom 96-well plate for $10 \mathrm{~min}$ at $1,100 \times g$ and incubated in culture medium for $48 \mathrm{~h}$ in low oxygen $\left(3 \% \mathrm{O}_{2}\right)$ atmosphere. After $48 \mathrm{~h}$, the newly formed neo-tissues were transferred to ultra-low attachment plate and cultured for $21 \mathrm{~d}$ in serum-free basal chondrogenic medium containing high-glucose DMEM, $62 \mathrm{mg} / \mathrm{L}$ L-ascorbic acid, $1 \%$ $\mathrm{P} / \mathrm{S}, 1 \mu \mathrm{g} / \mathrm{mL}$ dexamethasone, 1 : 1000 ITS in low oxygen $\left(3 \% \mathrm{O}_{2}\right)$ atmosphere. Chondrogenesis was induced in the control samples by adding $10 \mathrm{ng} / \mathrm{mL}$ TGF- $\beta 1$ (100-21C; PeproTech) and 100 ng/mL BMP2 (120-02C; PeproTech) to the basal chondrogenic medium. To investigate the effect of stimulated and non-stimulated CM on chondrogenesis, the spheroids were incubated with CM in the absence of growth factors. Half of the CM was replaced with fresh CM twice a week. Spheroids were harvested after $21 \mathrm{~d}$ and fixed in $10 \%$ formalin overnight for histological evaluation. Alcian blue solution (A5268, Sigma-Aldrich) was used for metachromatic staining of $4 \mu \mathrm{m}$-thick paraffin-embedded sections.

\section{Statistical analysis}

All statistical analyses were performed using IBM SPSS statistics version 24 (Chicago, IL, USA). Data were analysed using non-parametric KruskalWallis test, unless an exception was mentioned, and significance values were adjusted by Bonferroni correction for multiple comparisons. The level of significance was set at $p<0.05$. Results are presented as density graphs, where each donor plotted as a dot in the dataset.

\section{Results}

Comparative protein profiles in supernatants of different stromal cells by LC-MS/MS proteomics The MS secretomics data (identifier PXD011762) were deposited to the ProteomeXchange Consortium through the PRIDE partner repository (Vizcaíno et al., 2016). All cell types were characterised by MSC surface markers and retained similar characteristics, as shown by Islam et al. (2016). The cell secretome established in serum-free CM from each cell type (four unrelated donors per cell type) was analysed by LC-MS/MS proteomics. Only proteins identified in at least three donors in each group were considered for further analyses. Results showed more proteins identified in the supernatants of ACs (709) as compared to HFPSCs (641), SMSCs (567) and UCSCs (653) (Fig. 1a). Comparative analysis of identified proteins revealed 472 proteins present in the supernatants of all four cell types. Only a minor fraction of proteins was exclusively found in supernatants of specific cell types, including 50 differentially expressed by UCSCs, 44 by ACs, 22 by HFPSCs and 2 by SMSCs. Hierarchical clustering of identified proteins revealed two major clusters, where one cluster comprised the four donors of UCSCs and the second cluster comprised all stromal cells from adult tissues (Fig. 1b). Furthermore, among the stromal cells from adult tissues, the four AC donors were clearly separated from HFPSC and SMSC donors. Identified proteins were divided into six groups according to their functions using Gene Ontology Biological Process (GOBP) terms (Pazos and Chagoyen, 2009) (Fig. 2a). Qualitative comparison of proteins in different pathways revealed no major differences between cell sources. Proteins involved in ECM remodelling were abundant in the supernatants of all cell types. In addition, all stromal cells released similar percentage of proteins involved in immunoregulation $(\sim 20 \%)$ and secretion ( $13 \%$ ) (Fig. 2a).

Quantitative analyses of protein expression were performed using the LFQ approach (Patel et al., 2009) (Fig. 2b). Six volcano plots representing all possible comparisons showed differentially expressed proteins by plotting $\log _{10}$ of the fold change on the $\mathrm{X}$-axis and $-\log _{10}$ of the $p$-value on the $\mathrm{Y}$-axis for each comparison (e.g. HFPSCs vs. ACs). Results revealed the largest differences in protein expression between 
UCSCs and all other adult stromal cells (FDR $<0.01$ ). Proteins involved in cell signalling, such as TGF- $\beta 1$, PDGFD and MCP-1, were significantly upregulated in UCSCs (FDR < 0.01), while catabolic proteins, such as MMPs, serpins and complement factors, were downregulated as compared to stromal cells from adult origin (Fig. 2b). Notably, minor differences particularly in ECM remodelling proteins, such as MMPs and serpins, were observed while comparing stromal cells from cartilage and synovium (Fig. 2 b). Protein profiles belonging to specific pathways (ECM remodelling, cell communication and inflammation) were compared among the four cell types (Fig. 3). Several MMPs, serpins, some complement factors and heat shock proteins were significantly downregulated in UCSCs (FDR < 0.01). On the other hand, cell signalling molecules including MCP-1, integrin (ITG)- $\beta 1$, PDGFD, CSF-1, HLA-C and TGF- $\beta 1$ were more abundant in the supernatants of UCSCs.

Determination of cytokines and growth factors in supernatants by multiplex protein arrays

A panel of 18 selected cytokines involved in inflammation and immunoregulation was measured in the supernatants of all stromal cells. Only IL-4, IL-6, IL-8, IL-12 and IL-17 were detected in supernatants of all cell types, whereas GM-CSF, IFN- $\alpha$, IFN- $\gamma$, IL$1 \beta$, IL-1RA, IL-2, IL-2R, IL-5, IL-7, IL-13, IL-15 and
TNF- $\alpha$ were not detected in any of the supernatants. From the panel of chemokines, MCP-1, MIP- $1 \alpha$ and RANTES were detected in all supernatants, but eotaxin, IP-10, MIG and MIP-1 $\beta$ were not detected. Overall, the levels of IL-6, MCP-1 and PGE2 were increased in UCSCs supernatants as compared to other cell types, whereas the levels of IL-17, MIP- $1 \alpha$ and RANTES were decreased (Fig. 4). The concentration of IL-17 and MIP- $1 \alpha$ was significantly lower in the UCSC supernatant as compared to AC supernatant and the levels of PGE2 was significantly higher in UCSC supernatants as compared to HFPSC supernatant (Fig. 4). With regards to the expression of proteases, only MMP-13 was not detectable, whereas MMP-1, MMP-3, MMP-7 and MMP-9 were detected to some degree in all serum-free CM (Fig. 5). The secretion of MMP-1, MMP-3, MMP-7 and MMP-9 was in general lower in UCSCs as compared to all other cell types. Significant differences were found for MMP-3 and MMP-7 when comparing UCSCs and ACs. The anabolic growth factors TGF- $\beta 1$, BMP-2 and bFGF were detected at low levels in supernatants of the four cell sources, whereas IGF-1 and PDGF$\mathrm{AB}$ could not be detected. Additionally, TGF- $\beta 1$ was significantly elevated in UCSCs as compared to HFPSCs (Fig. 5). To check for possible effects of serum supplementation on the production of cytokines by MSCs, the expression of TNF- $\alpha$, IFN- $\gamma$,

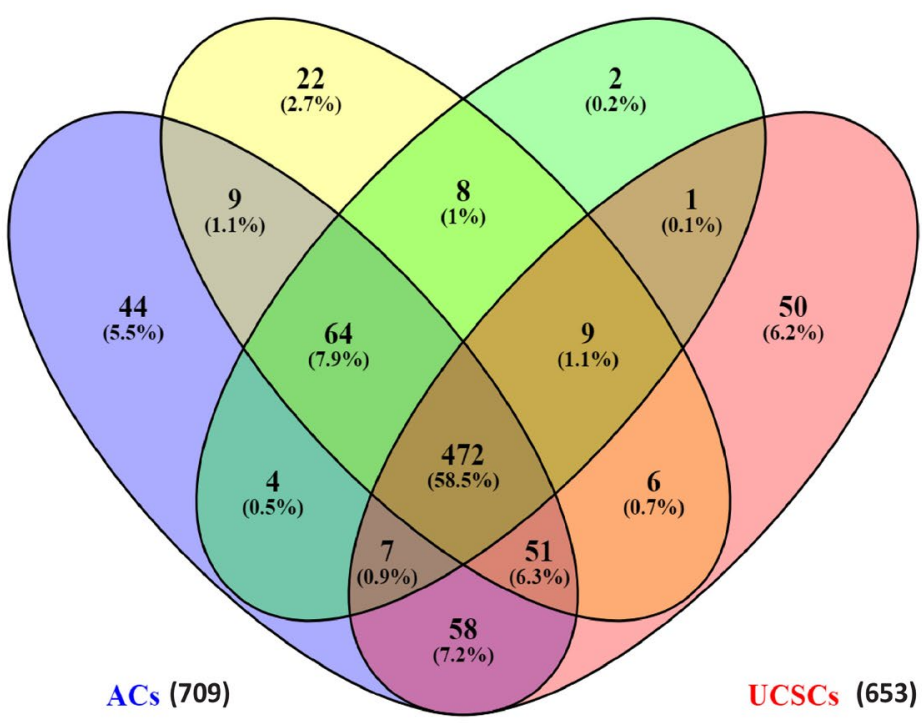

b
Fig. 1. Hierarchical clustering of identified proteins from secretomes of ACs, HFPSCs, SMSCs and UCSCs. (a) Venn diagram depicts the percentage of identified proteins shared among the four different stromal cell types $(n=4$ donors/cell sources). (b) Dendrogram shows two major clusters of four different stromal cell types. All cell sources from adult mesenchymal origin clustered together, whereas the four donors of UCSCs from extra-embryonic origin clustered separately. 
Cell communication \& signaling

Catabolic process \& proteolysis

ECM component

Immunoregulatory

Secretion \& growth

Intracellular

Others
ACs

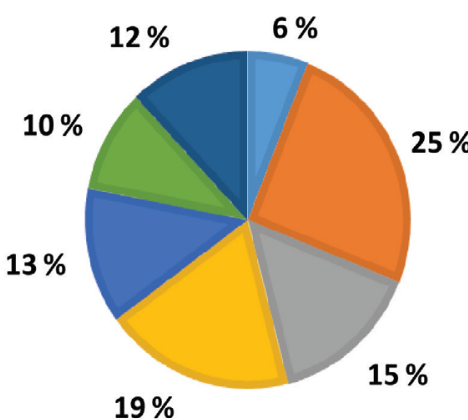

SMSCs

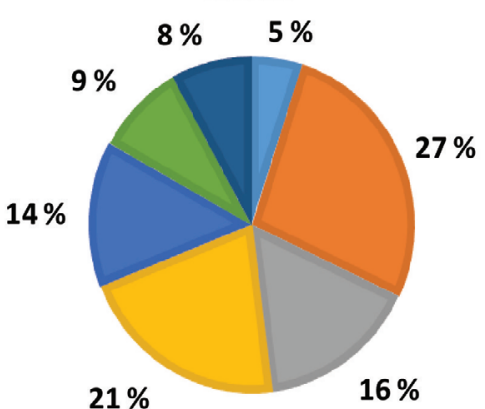

HFPSCs
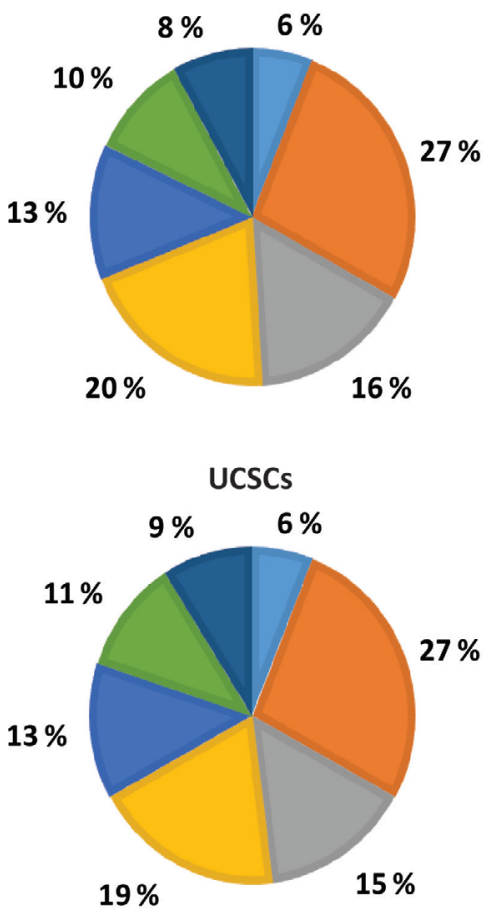

b

HFPSCs vs ACs

SMSCs vs ACs

HFPSCs vs SMSCs
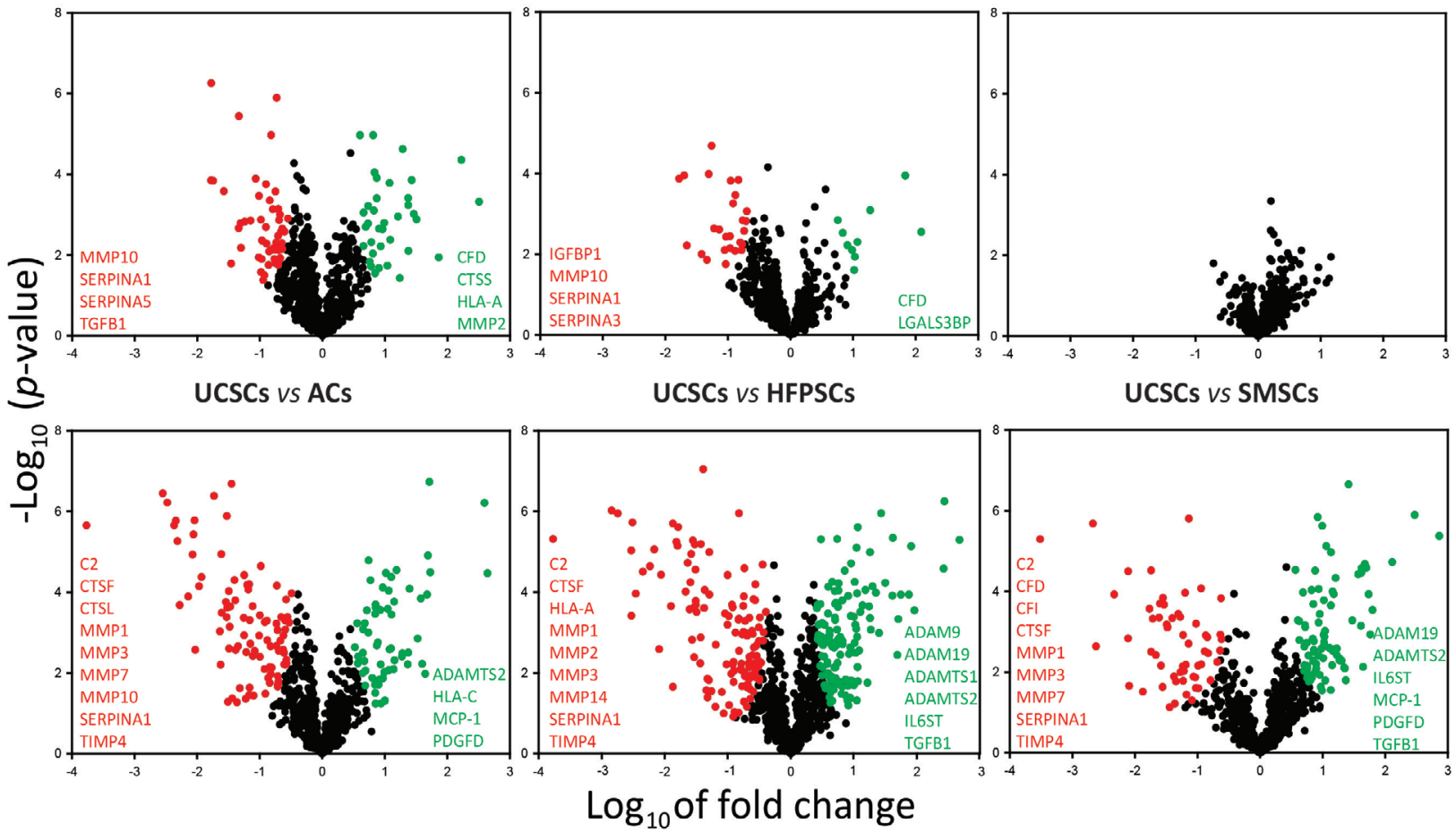

Fig. 2. Protein expression analysis by LC-MS/MS from CM of ACs, HFPSCs, SMSCs and UCSCs. (a) Distribution of identified proteins into six main categories according to their function annotated using GOBP terms. (b) Volcano plots illustrate the results of the six sets of statistical comparisons made between HFPSCs vs. ACs, SMSCs vs. ACs, HFPSCs vs. SMSCs, UCSCs vs. ACs, UCSCs vs. HFPSCs and UCSCs vs. SMSCs. These plots show each protein with $-\log _{10}$ ( $p$-value) and $\log _{10}$ of fold change of the comparison on the $\mathrm{Y}$-axis and $\mathrm{X}$-axis, respectively. Proteins with larger fold change and lower $p$-value are plotted further away from zero on each axis. Proteins that are significantly up- and down-regulated $(p<0.01)$ are represented in green and red, respectively. 
IL-6 and IL-12 in both serum-containing and serumfree CM from all four cell types was analysed. From the analysed cytokines, only the expression of IL-6 was considerably changed in the presence of serum (Fig. 6).

\section{UCSC supernatants exerted stronger} immunosuppressive effects on activated PBMCs To investigate the immunomodulatory effects of cell supernatants on activated PBMCs, in vitro lymphocytes proliferation and migration assays were performed (Fig. 7a). PHA-activated PBMCs were incubated for $5 \mathrm{~d}$ in the presence or absence of serumcontaining CM from the different cell sources. The proliferation assay revealed that UCSC supernatants blocked PBMC proliferation $(p=0.06)$ when compared with PHA-treated controls (Fig. 7a,b). CM from ACs did not block PBMC proliferation, while HFPSCs $(71 \pm 5 \%)$ and SMSCs $(68 \pm 3 \%)$ had a minor effect. In the migration assay, both UCSCs and SMSCs blocked the migration of activated PBMCs as compared to positive controls $(38 \pm 2.5 \%$ and $38 \pm 1.2 \%$ vs. $44.2 \pm 0.5 \%$, respectively) (Fig. 7 b). To further investigate the immunomodulatory effects of MSC supernatants, the expression of TNF- $\alpha$ and IFN- $\gamma$ in PBMCs-CM was measured. Values were normalised against residual expression levels present in supernatants of stromal cells. Supernatants from HFPSCs and SMSCs stimulated the production of
TNF- $\alpha$ and IFN- $\gamma$ above the levels achieved by PHA treatments. Importantly, supernatants from UCSCs suppressed the production of both TNF- $\alpha$ and IFN- $\gamma$ by activated PBMCs, reaching significant differences when compared to HFPSCs (Fig. 7c).

Immunomodulatory properties of supernatants after stimulation of MSCs with pro-inflammatory cytokines

TGF- $\beta 1$, PGE2, IL-4 and IL-10 were measured in the supernatants of stimulated and non-stimulated stromal cells by ELISA. Only TGF- $\beta 1$ and PGE2 were detected in the supernatants of both stimulated and non-stimulated cells (Fig. 8a), whereas IL-4 and IL-10 were not detected. In supernatants of cells stimulated with pro-inflammatory cytokines, the level of TGF- $\beta 1$ was increased in AC cultures $(p=0.09)$ but unchanged in SMSC and UCSC cultures. The amount of secreted PGE2 significantly increased in the supernatants of stimulated ACs and SMSCs (Fig. 8a). In addition, PBMC proliferation assay demonstrated superior blocking capacity of supernatants from primed adult stromal cells but not from UCSCs (Fig. 8b).

UCSC supernatants exerted superior antiinflammatory effects on M1 activated macrophages Macrophage polarisation assays were performed as previously reported (Ambarus et al., 2012; Vogel et al., 2014). A panel of co-stimulatory molecules and
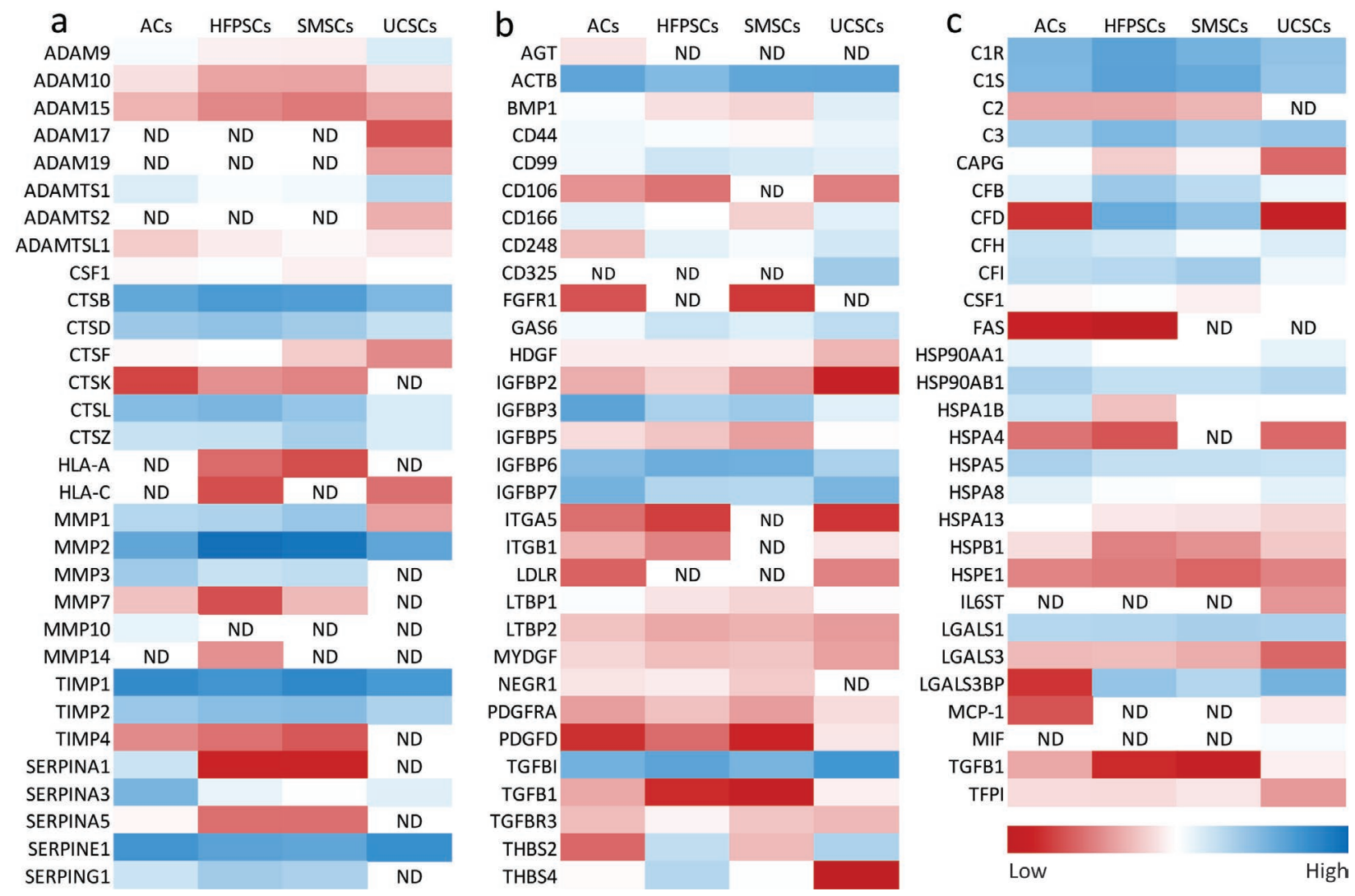

Fig. 3. Comparative expression of selected proteins identified by LC/MS-MS belonging to specific pathways. Heat map showing proteins involved in (a) ECM remodelling (proteases and inhibitors), (b) cell signalling (growth factors) and (c) inflammation/immune responses. Down-regulated proteins are indicated in red, whereas up-regulated proteins in blue. 
cytokines to characterise macrophage polarisation was chosen based on validation tests using different stimulants. Divergent expression of these markers was observed in the presence of different stimulants. In addition, IL-10 expression resulted to be an irrelevant marker for M2 polarised macrophages. In the validation test, increased IL-10 production was observed in the presence of LPS and IFN- $\gamma$ (for M1 induction) as compared to dexamethasone or TGF- $\beta 1$ and IL-4 stimulation (for M2 induction) (data not shown). These discrepancies are also reported by Chanteux et al. (2007) and Vogel et al. (2014). Moreover, CD163 was a suitable marker for dexamethasonestimulated M2 polarised macrophages but not for TGF- $\beta 1$ and IL-4 stimulation. The discrepancy concerning the expression of M2 markers is also demonstrated by Jaguin et al. (2013).

The immunomodulatory effects on M1 polarised macrophages were investigated by characterisation of surface marker expression (CD40, HLA-DR, CD64, CD80, CD86) and inflammatory cytokines release (Fig. 9). Supernatants from all stromal cell types suppressed the surface expression of HLADR on activated macrophages, whereas only UCSC supernatants were able to significantly suppress the expression of CD40. On the other hand, supernatants from ACs were able to significantly increase the expression of the co-regulatory receptors CD80 and CD86 above the levels of M1 activation (Fig. 9b). In contrast to ACs and UCSCs, supernatants from HFPSCs and SMSCs increased the surface expression of CD64 above M1 activation levels. None of the supernatants was able to alter the expression of the M2 phenotype marker CD163. With regards to cytokine profiles, $\mathrm{CM}$ from all cell types was able to reduce the production of TNF- $\alpha$, IL- 6 and IL- 12 by M1-M. Of note, a significant reduction of IL-6 and IL-12 concentration was only achieved by UCSCs (Fig. 9c).

\section{Effects of UCSC CM on AC chondrogenesis}

To check the chondrogenic potential of UCSC secretomes, the effects of UCSCs-CM on the expression of cartilage signature genes and the tissueforming capacity of dedifferentiated chondrocytes were investigated. Incubation with UCSCs-CM positively influenced gene expression of COL2A1, SOX9 and ACAN as compared to non-stimulated
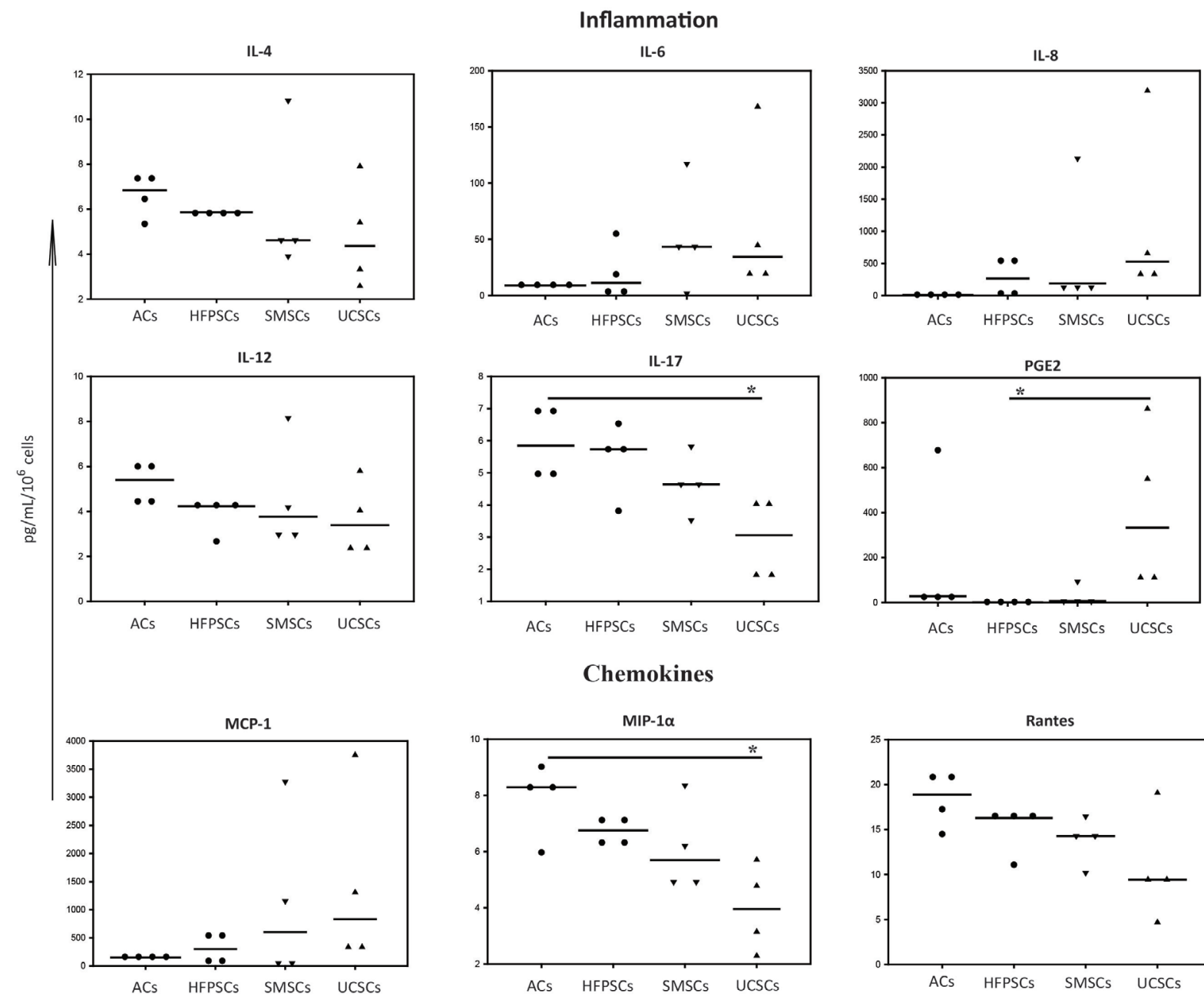

Chemokines
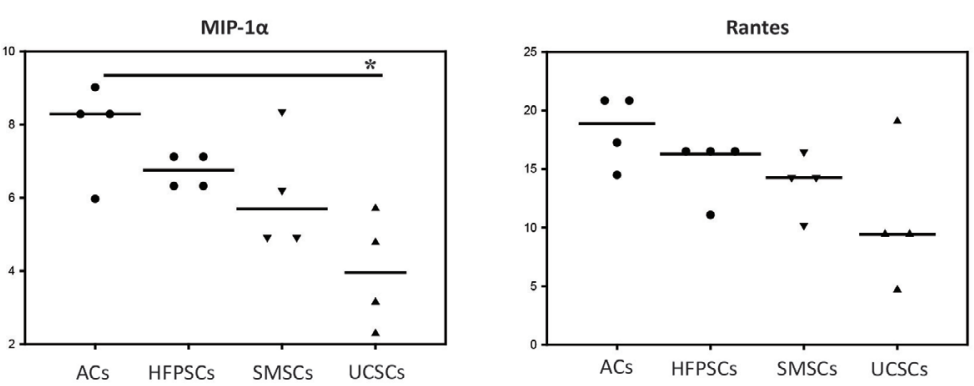

Fig. 4. Comparison of cytokines and chemokines from CM of ACs, HFPSCs, SMSCs and UCSCs. Dot density shows concentration of cytokines involved in inflammation (IL-4, IL-6, IL-8, IL-12, IL-17 and PGE2) and chemokines (MCP-1, MIP-1 $\alpha$ and RANTES) detected in supernatants of four different stromal cell types. ${ }^{*} p<0.05 ; n=4$ donors/cell sources. 


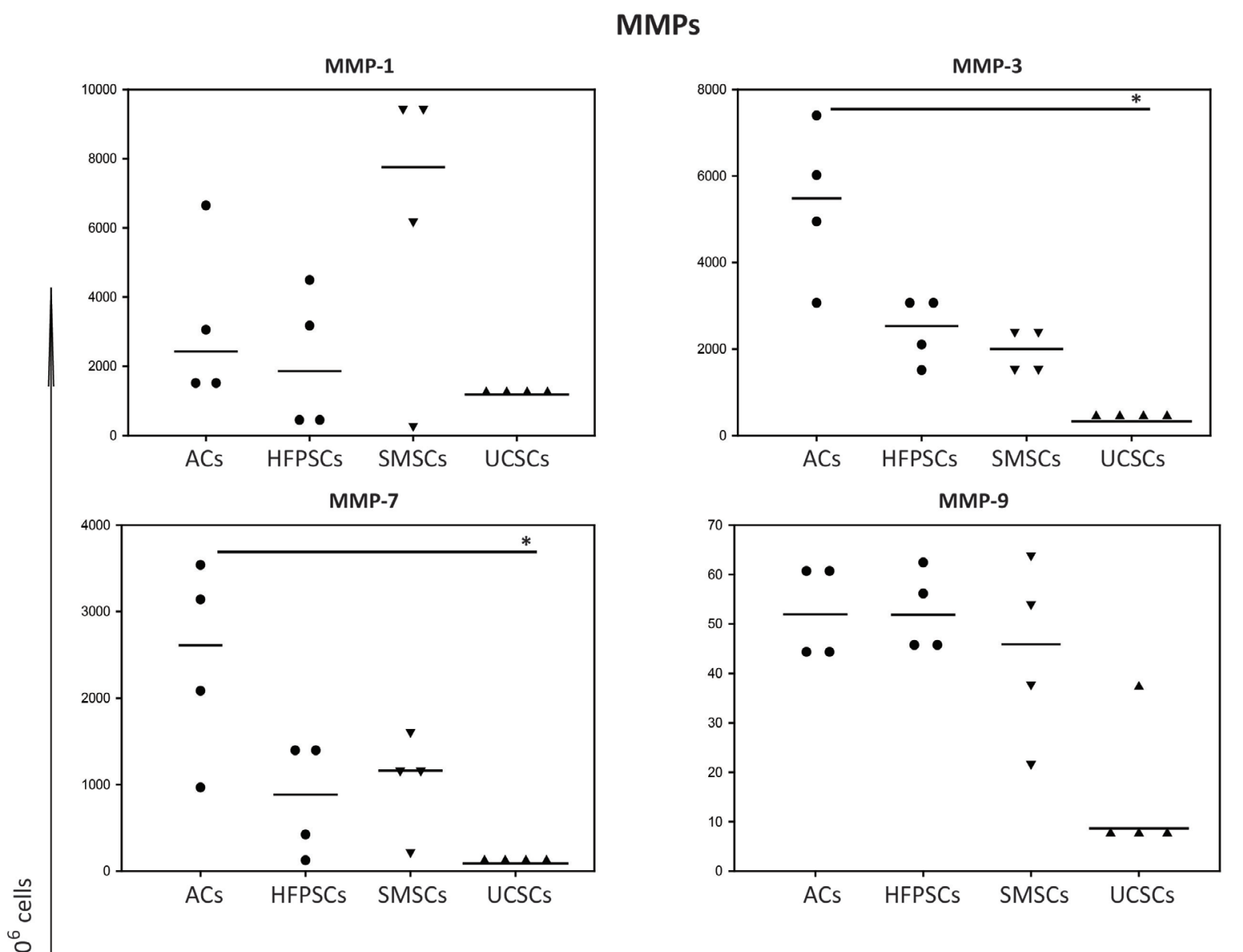

\section{Growth Factors}
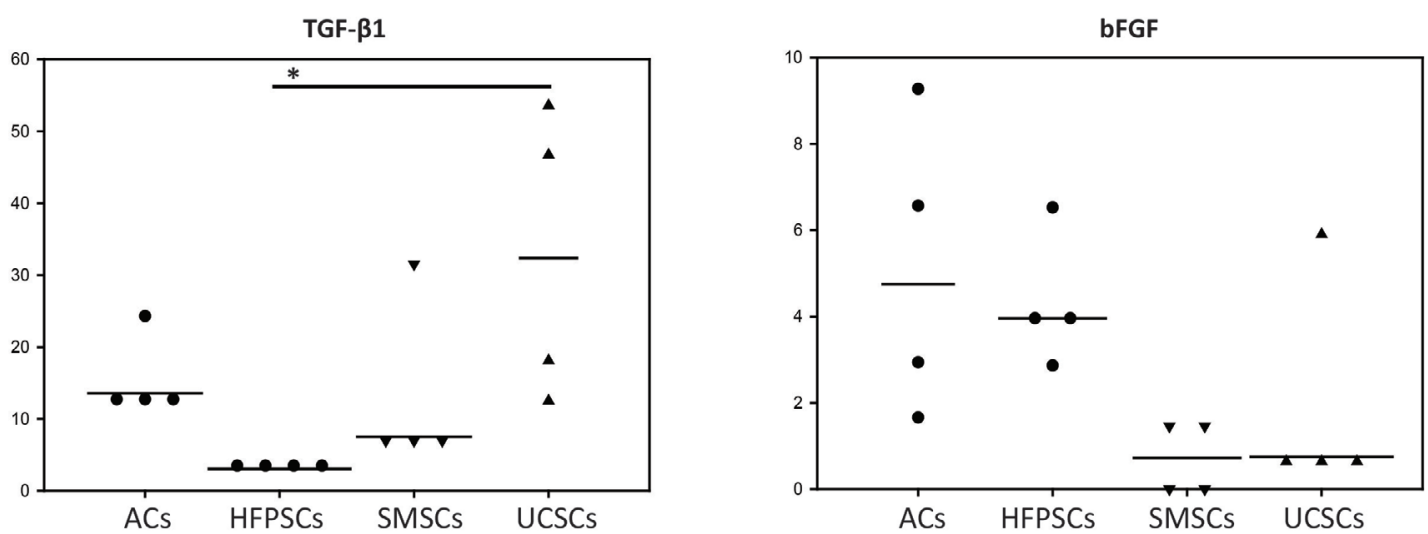

BMP-2

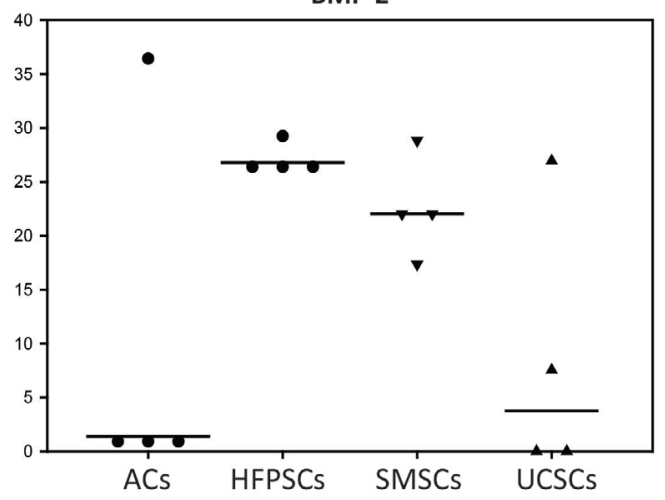

Fig. 5. Comparison of MMPs and anabolic factors from CM of ACs, HFPSCs, SMSCs and UCSCs. Dot density shows the concentration of MMPs (MMP-1, MMP-3, MMP-7 and MMP-9) and growth factors (TGF- $\beta 1$, bFGF and BMP-2) detected in supernatants of four different stromal cell types. ${ }^{*} p<0.05 ; n=4$ donors/cell sources. 
control P3 chondrocytes (Fig. 10); however, the differences were not significant except for ACAN. The CM of both stimulated and non-stimulated UCSCs significantly upregulated the expression of ACAN as compared to the control P3 chondrocytes (Fig. 10). On the other hand, in the 3D culture assays, no differences were observed in cartilage neo-tissue formation by histology when comparing pellets incubated in the presence or absence of UCSCs-CM (Fig. 11).

\section{Discussion}

The main objective of the study was to ascertain which source of stromal cells possesses the most favourable secretome to promote tissue repair. Given the importance of the MSC paracrine signalling, large-scale comparative analyses of cell secretomes were performed and functional studies with cell supernatants were conducted on immune cells to compare the constitutive immunomodulatory capabilities of different MSCs. Overall, the results demonstrated that stromal cells from umbilical cord matrix exhibited superior anti-inflammatory and trophic effects when compared with adult ACs, HFPSCs and SMSCs.

All cell sources were expanded in monolayer cultures in the serum-supplemented media for some weeks, as done in standard cell transplantation procedures. To facilitate the analyses of secretory profiles by LC-MS/MS proteomics, the media were conditioned under serum-free conditions. Multiplex protein arrays were performed with the same serumfree CM that was used for proteomics, allowing direct comparisons of results. However, functional assays with immune cells were performed with serumsupplemented CM, as serum deprivation affects proliferation and induces apoptosis in lymphocytes and macrophages, respectively (Sato et al., 2009; Wei et al., 2006). Short periods of serum deprivation do not affect the cell viability of mesenchymal cells (Boraldi et al., 2008). However, some changes in the secretome could occur upon changes in serum supplementation. Significantly higher expression of IL-6 was only observed in the presence of serum in all four cell types (Fig. 6). Although only minor phenotypic changes were expected in cells associated with serum presence, alterations in the expression of some bioactive molecules could occur and should be taken into consideration.

Currently, MSCs are viewed as "drugstores" with the potential to modulate the phenotype, migration and activation of resident tissue and inflammatory cells (Caplan and Correa, 2011). This has led researchers to study MSC-mediated paracrine effects and profiles of secreted proteins from different mesenchymal stromal cell types. Previous studies comparing secretory profiles from different MSC sources highlight the existence of differentially expressed factors, with impact on angiogenesis, matrix remodelling, inflammation and immunosuppression (Amable et al., 2014; Dabrowski et al., 2017; Hsiao et al., 2012; Li et al., 2015). The qualitative analyses using a large-scale proteomic approach revealed similar protein profiles, where most of the identified proteins were present in all cell supernatants. However, after hierarchical clustering of protein profiles from all donors, UCSC secretomes single out from the other adult cell sources (Fig. 1b). Quantitative analyses of the secretome data revealed that proteins involved in cell signalling, such as TGF- $\beta 1$ and PDGFD, were upregulated in UCSC supernatants, while catabolic proteins, such as MMPs, serpins and complement factors, were downregulated when compared to stromal cells from adult origin. TGF- $\beta 1$ is a master driver of chondrogenesis and has pleiotropic effects in OA pathogenesis (Tang et al., 2015; Zhang et al., 2015; Zhen et al., 2013). In addition, TGF- $\beta 1$ has antiapoptotic effects (Rehman et al., 2004). Observations from other studies are disparate and include cell sources that were not used in the present study;

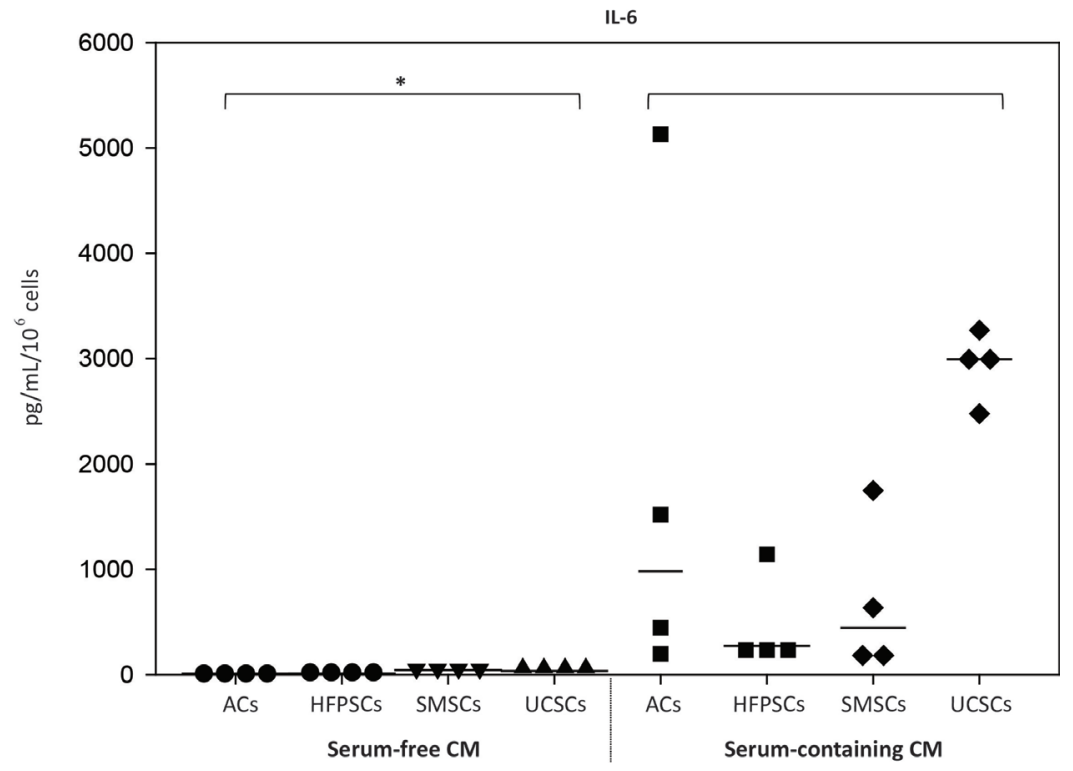

Fig. 6. Cytokine expression by all cell sources in serum-free and serum-supplemented conditions. The secretion of selected cytokines and factors was assessed by ELISA. TNF- $\alpha$, IFN- $\gamma$ and IL-12 were not detected. Data were analysed using Mann-Whitney U comparison between serum-free and serumcontaining $\mathrm{CM}$ of each cell type. ${ }^{*} p<0.05 ; n=4$ donors/cell sources. 
a

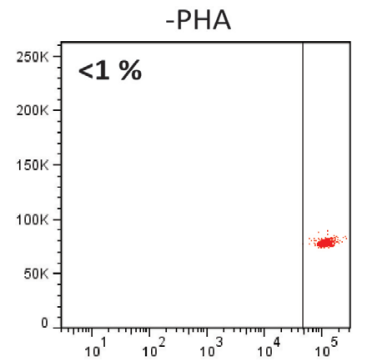

忈
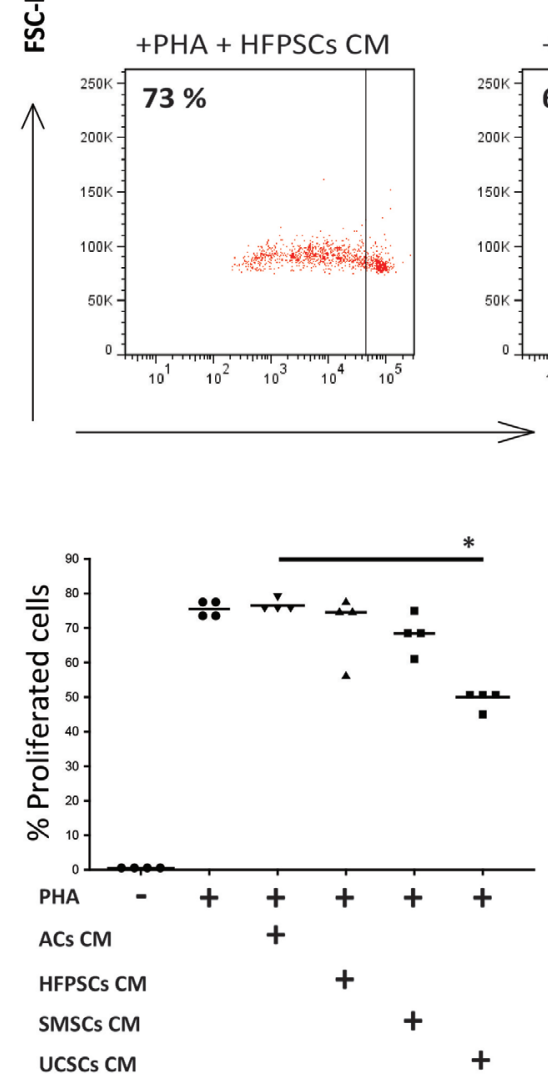

C

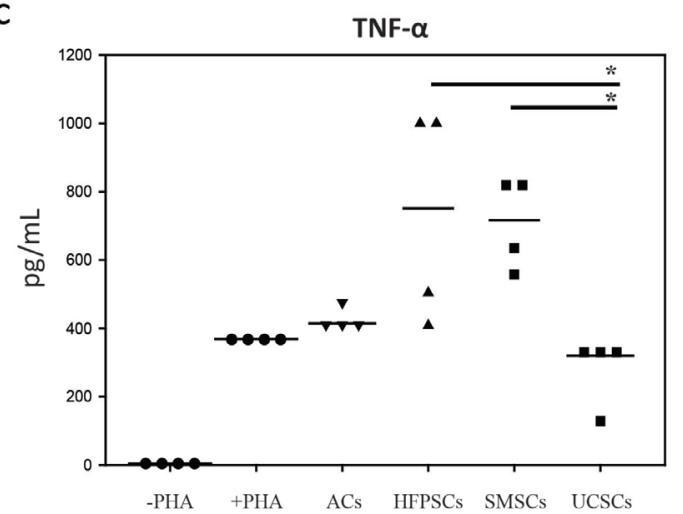

b
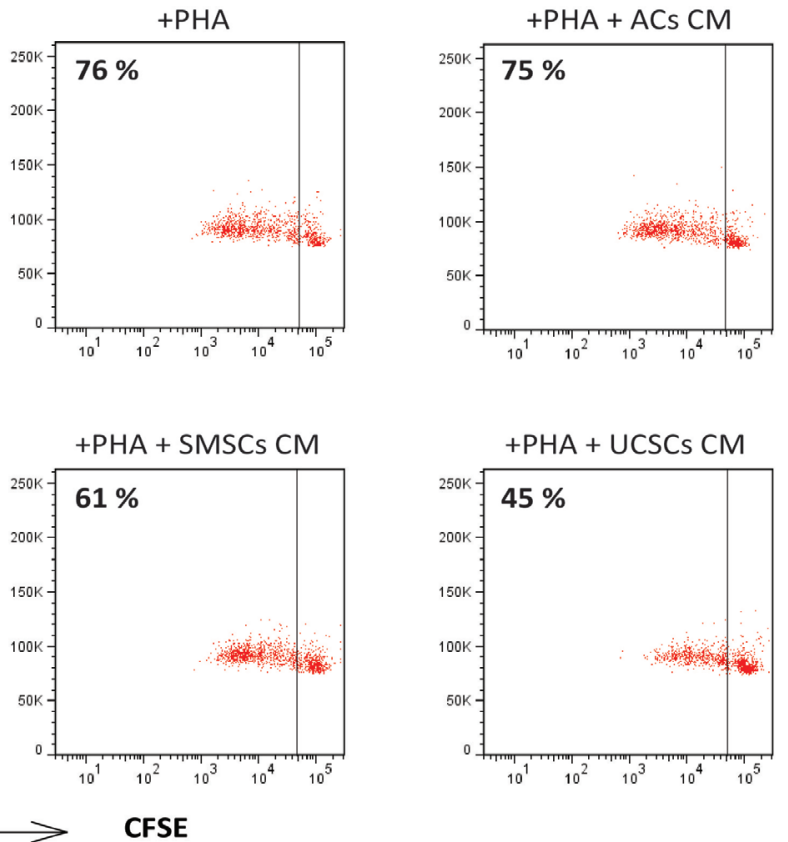

CFSE
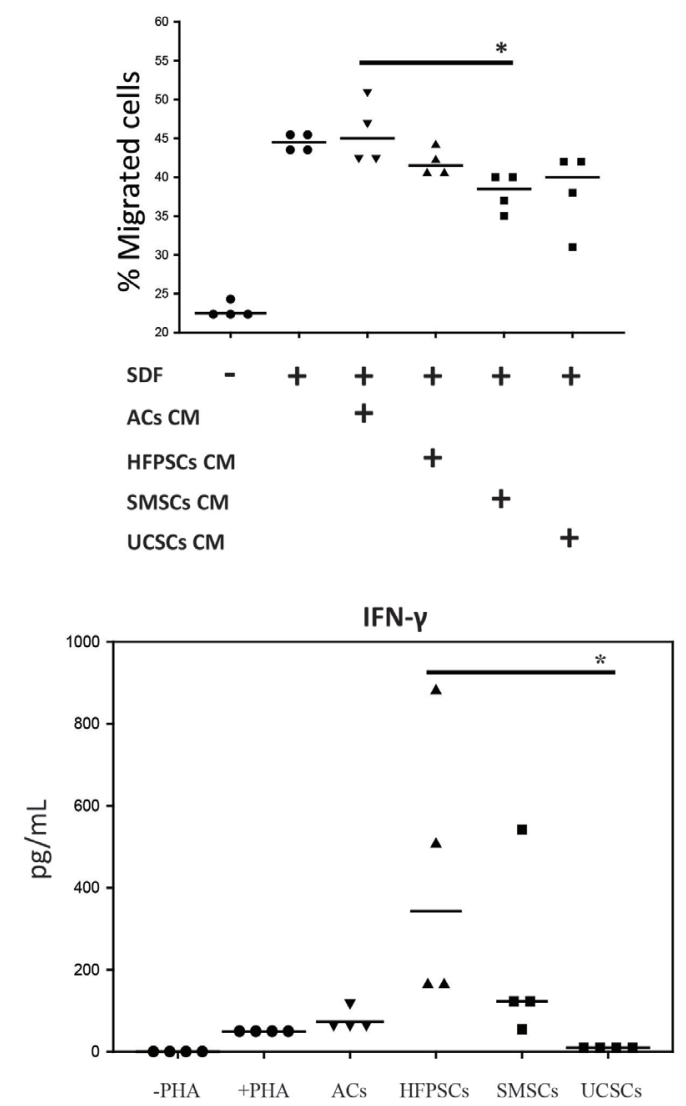

Fig. 7. Inhibition of PBMC activation by CM. (a) PBMC proliferation assay: representative flow cytometry dot plots depict the percentage of proliferating PBMCs stimulated with $10 \mu \mathrm{g} / \mathrm{mL}$ of PHA in the presence and absence of CM from the four different stromal cell types. (b) Quantitative analyses of PBMCs proliferation and migration in the presence and absence of CM from four different stromal cell types. $100 \mathrm{ng} / \mathrm{mL}$ SDF-1 was used for chemo-attraction in migration assays. (c) Total concentration of TNF- $\alpha$ and IFN- $\gamma$ detected in $10^{6}$ cells/well PBMCs-CM after incubation with PHA and CM from four different stromal cell types. ${ }^{*} p<0.05 ; n=4$ donors/cell sources. 
however, the superior anabolic phenotype of UCSCs, including the highest expression of TGF- $\beta 1$ among the compared cell types, is also observed by Dabrowski et al. (2017). Data from the multiplex protein analyses revealed a significant reduction of MMPs and increased expression of TGF- $\beta 1$ by UCSCs, thus reasserting observations made in the large-scale proteomic approach. Altogether, these observations highlighted the less catabolic phenotype of UCSCs when compared to the three other adult MSCs.

The immunomodulatory profile of the different MSCs was also investigated by proteomics and multiplex arrays. Secretome analyses revealed comparable expression of complement components, heat-shock proteins, galectins and immunoregulators, such as CSF-1, MCP-1, MIF and TGF- $\beta 1$, among the different cell sources. The data from multiplex protein arrays showed enhanced expression of the immunomodulators IL-6, MCP-1 and PGE2 and reduced expression of IL-17 and MIP- $1 \alpha$ in UCSCs. Notably, stimulation of stromal cells with proinflammatory cytokines increased the expression of PGE2 in all cell types. However, a limitation of the study was the relatively low number of biological replicates, where the inclusion of more biological replicates could prove to be statistically significant for most of the analysed cytokines. IL-6 has an omnidirectional role in maintaining biological functions, whereas it has deleterious effects in the joint (Poree et al., 2008; Sui et al., 2009). However, selective depletion of IL-6 in animals is associated with accelerated joint degeneration upon ageing (de Hooge et al., 2005). Bouffi et al. (2010) demonstrate IL-6-dependent inhibition of local inflammation in experimental arthritis. MCP-1 (also called CCL2), MIP-1 $\alpha$ (CCL3) and IL-17 are all potent inflammatory factors mediating recruitment and activation of myeloid cells. Their presence is associated with cartilage degeneration and progression of OA (Appleton et al., 2015; Snelling et al., 2017; Wang et al., 2017; Xu et al., 2015; Zhao et al., 2015). IL-17 inhibits chondrogenesis and promotes MMPs in chondrocytes (Benderdour et al., 2002; Kondo et al., 2013). PGE2 regulates phenotype and functions of pro-inflammatory macrophages and natural killer (NK) cells (Manferdini et al., 2017), however, the overall role of this factor in OA progression and a

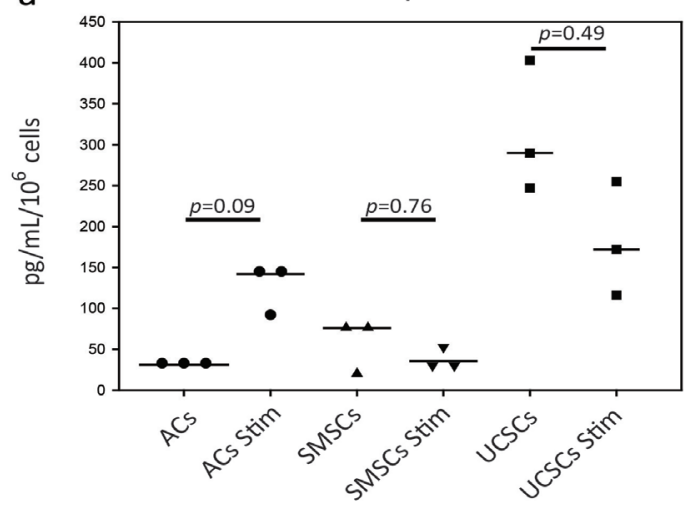

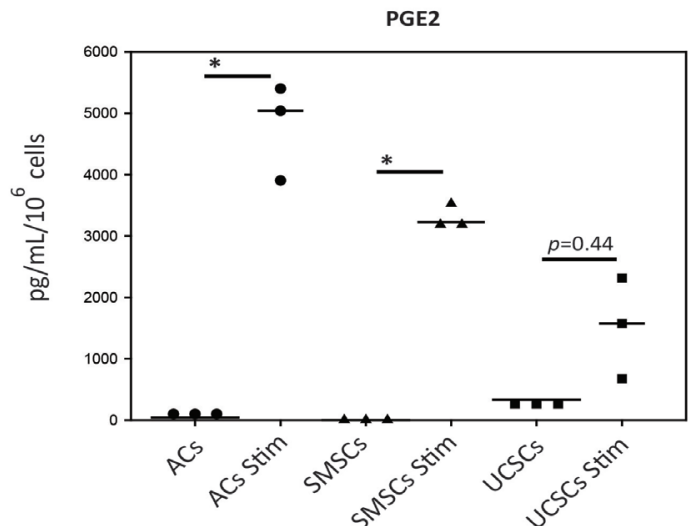

b

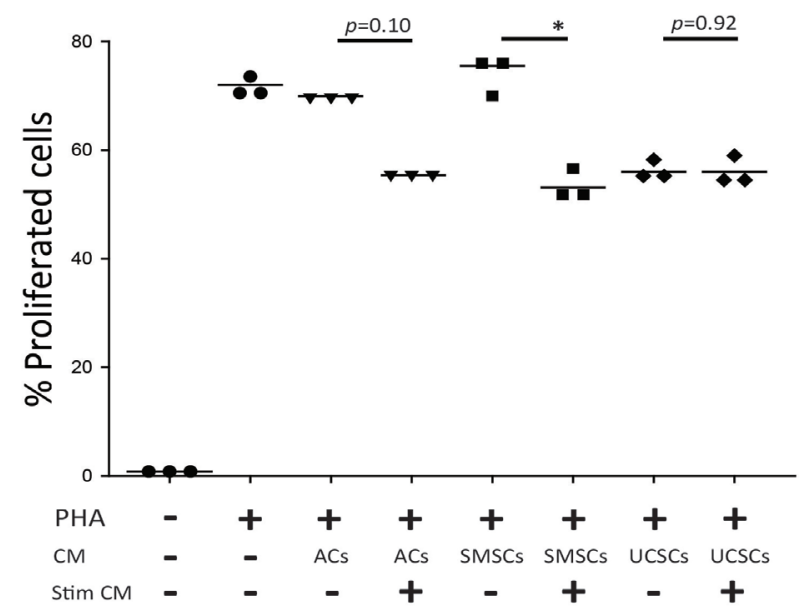

Fig. 8. Immunomodulatory properties of ACs, SMSCs and UCSCs after stimulation with TNF- $\alpha$ and IFN- $\gamma$. Cells in monolayer culture (70-80\% confluence) were stimulated for $48 \mathrm{~h}$ with $50 \mathrm{ng} / \mathrm{mL}$ each of TNF- $\alpha$ and IFN- $\gamma$. Data were analysed using Mann-Whitney U comparison between non-stimulated and stimulated CM of each cell type. (a) Dot density shows the concentration of TGF- $\beta 1$ and PGE2 detected in supernatants of non-stimulated and stimulated cell types. (b) PBMC proliferation assays in the presence of non-stimulated and stimulated CM of ACs, SMSCs and UCSCs. ${ }^{*} p<0.05 ; n=3$ donors/cell sources. 
cartilage homeostasis is still controversial (Bouffi et al., 2010; Miwa et al., 2000; Otsuka et al., 2009). Despite the difficulty to reach general conclusions due to the pleiotropic nature of many chemokines and cytokines, the observations based on the global expression of released factors indicated that UCSCs displayed a more immunosuppressive and anti-inflammatory phenotype than their adult counterparts.

To investigate further the paracrine potential of the different MSCs on immunomodulation, functional assays were conducted on lymphocytes and macrophages. Results using functional assays

a
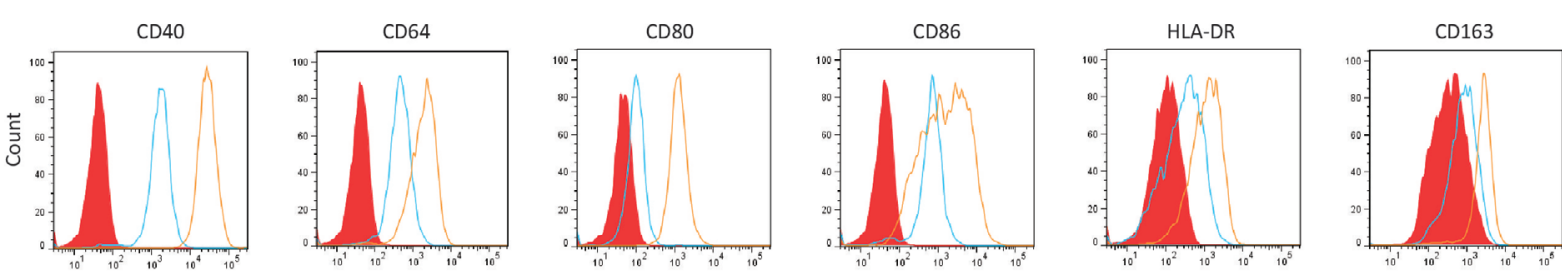

b
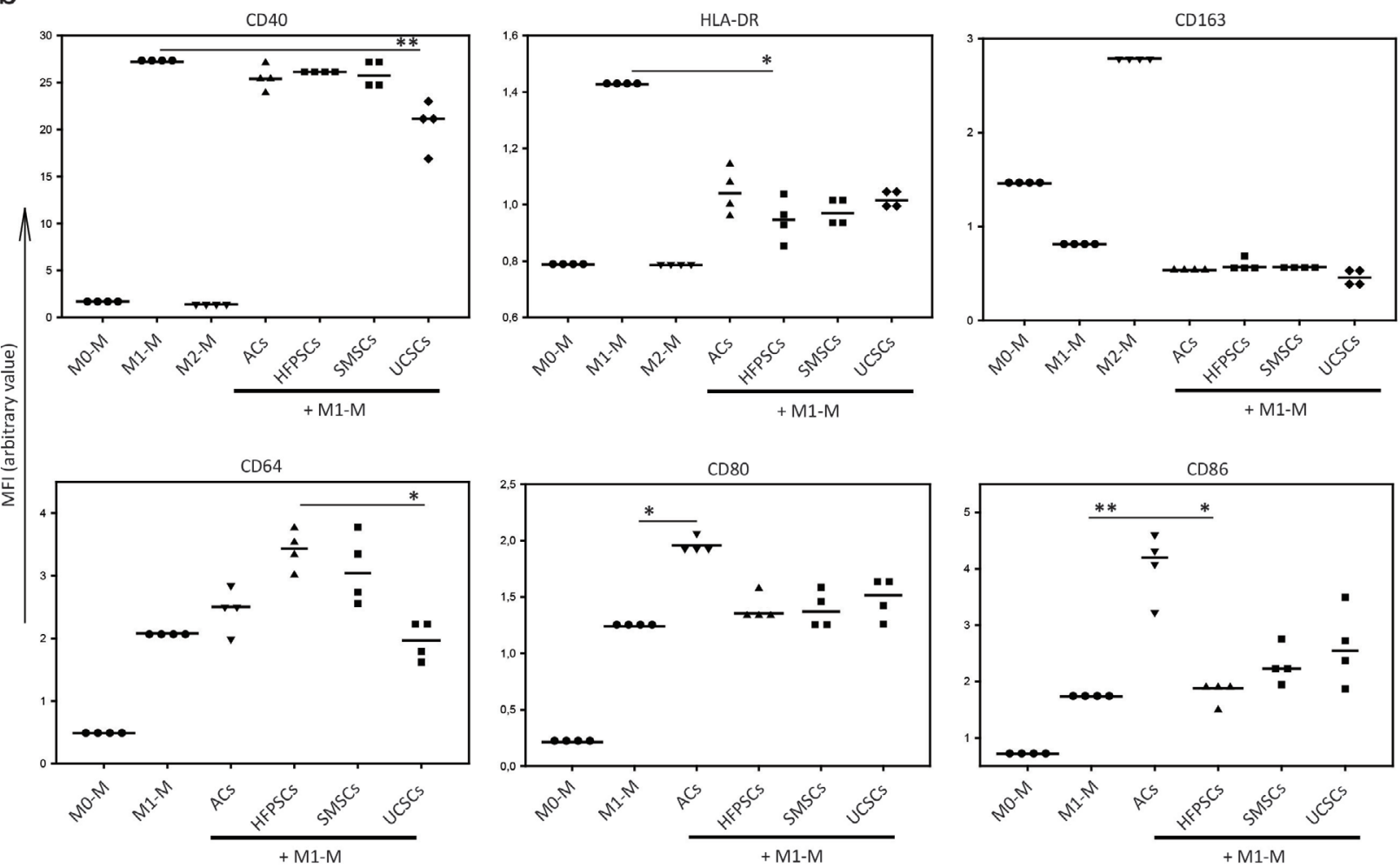

C
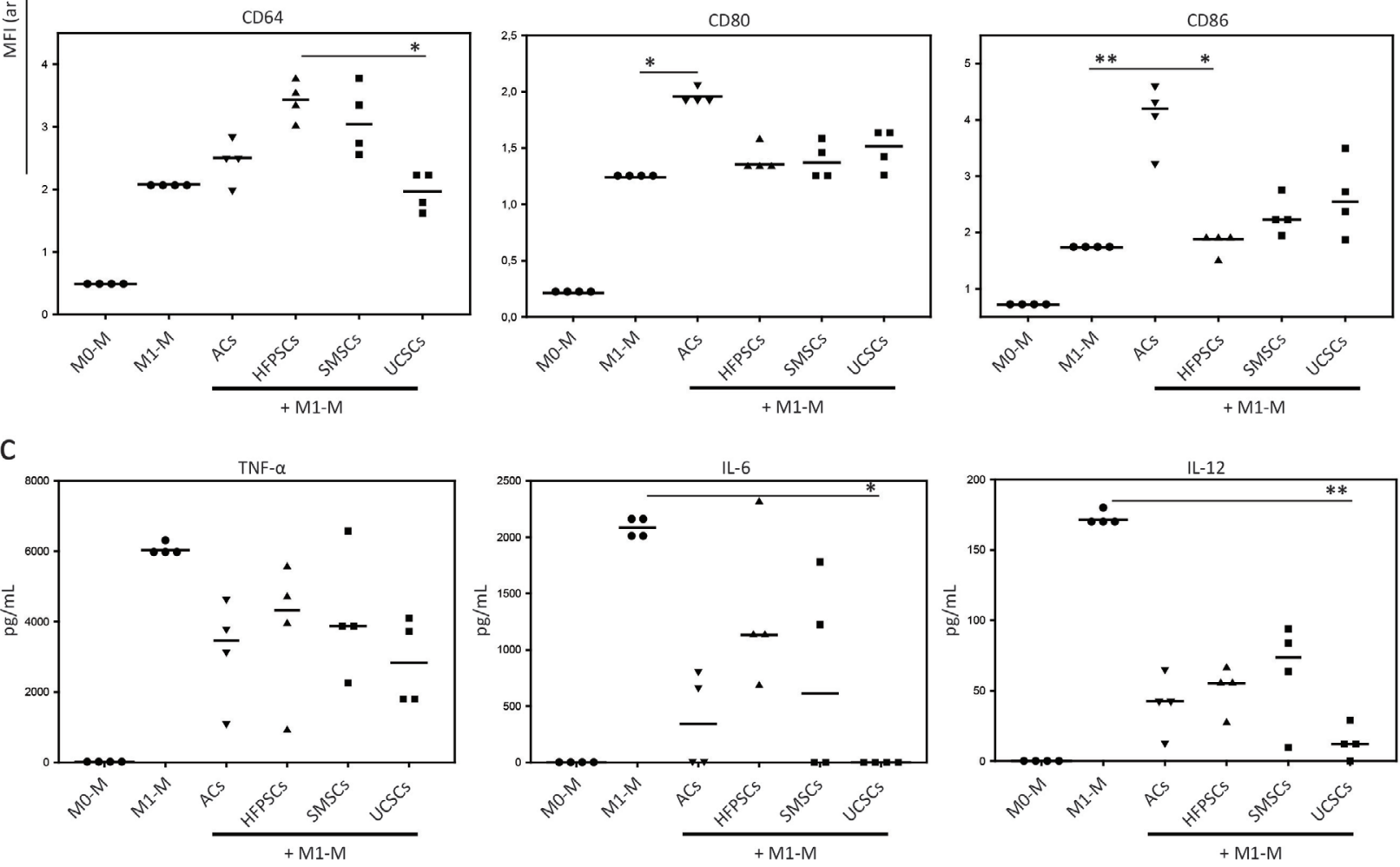

Fig. 9. UCSC secretomes could modulate macrophage-mediated inflammation. (a) Characterisation of surface molecules during polarisation of M0-M into M1-M (CD40, CD64, CD80, CD86 and HLA-DR) and M2-M (CD163) by flow cytometry. Red, blue and orange peaks represent isotype control, M0-M and activated macrophages, respectively. (b) Dot density depicts M1-M activation and distinct blocking of M1-M activation by CM from ACs, HFPSCs, SMSCs and UCSCs. M2-M polarisation was used as a negative control for surface expression of CD40 and HLA-DR. (c) Levels of TNF- $\alpha$, IL-6 and IL-12 detected in macrophage culture CM $\left(2.5 \times 10^{6}\right.$ cells/well $)$ after incubation with CM from four different stromal cell types. ${ }^{*} p<0.05$; ** $p<0.005 ; n=4$ donors/cell sources. 
harmonised with protein profiles, highlighting the superior immunosuppressive phenotype of UCSCs as compared to the other MSCs. The MSC ability to regulate inflammation and immunity has been the focus of intense research over recent years (Donders et al., 2018; von Bahr et al., 2012). Many in vitro studies show that mesenchymal cells from multiple sources, including differentiated connective tissue cells, such as chondrocytes and fibroblasts, have the potential to regulate inflammation and T-cell functions to some extent (Bouffi et al., 2011; Lohan et al., 2016). Still, there is no consensus on which cell source is the most powerful in this respect. Most published studies compare bone marrow, adipose tissue and foetal tissues with different outcomes. Some comparative studies demonstrate that bone marrow MSCs have slightly superior immunosuppressive capacity than In line with the observations of the present study, some groups observe superior immunosuppressive abilities by MSCs from cords (Jin et al., 2013; Najar et al., 2012). The chondro-inductive potential of UCSC supernatants on dedifferentiated chondrocytes was also tested in the present study. Whilst cartilage reference genes were upregulated after incubation with UCSCs-CM, no clear differences where observed in 3D neo-tissue formation in vitro. These results other MSCs (Heo et al., 2016; Karaoz et al., 2017).

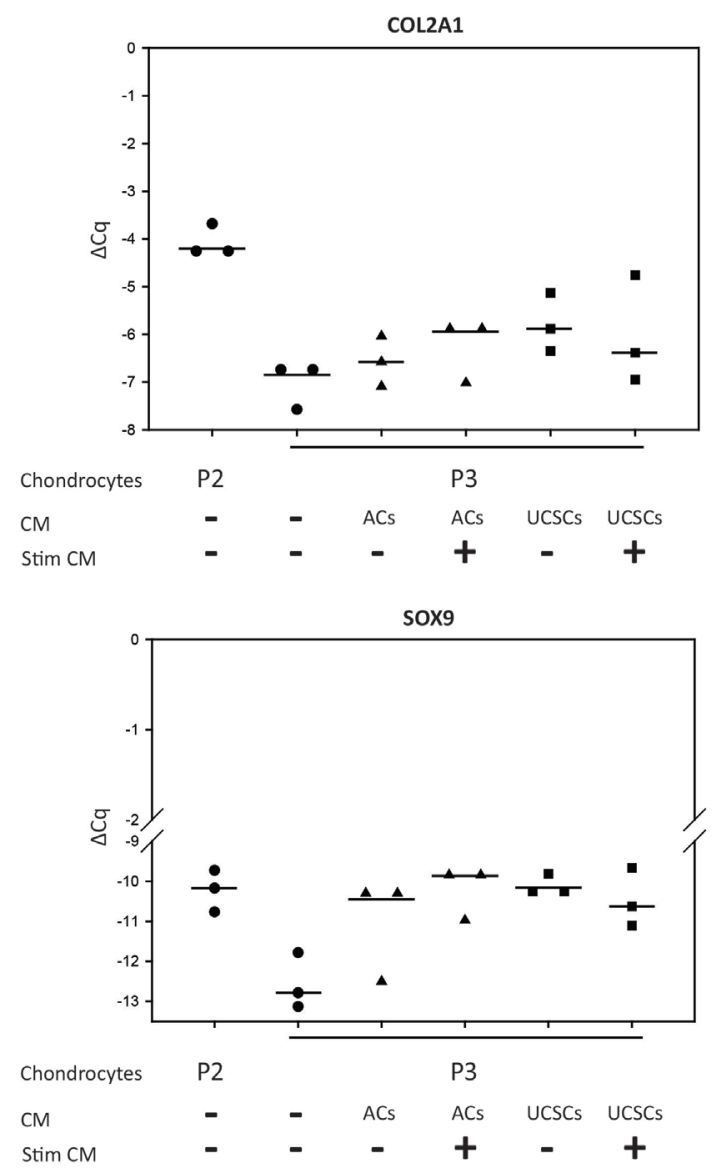

put forward the anabolic potential of the UCSC secretome; however, the concentration of anabolic factors, such as TGF- $\beta 1$, in supernatants remained insufficient to trigger proper chondrogenesis from dedifferentiated chondrocytes.

Priming of MSCs is extensively documented and is recommended as a mandatory step to unleash the full immunosuppressive potential of MSCs (GomezAristizabal et al., 2017; Najar et al., 2012; van Buul et al., 2012). In the present study, stimulation of adult stromal cells with pro-inflammatory cytokines altered the expression of some immunoregulatory factors and increased the blocking effects over PBMCs by adult MSCs (Fig. 8). On the other hand, the effects exerted by primed UCSCs on PBMC proliferation were unchanged. These differences could be due to early embryonic differentiation of the cell phenotypes. Notably, constitutive immunoregulation by nonstimulated UCSCs is observed in an OA rabbit model (Saulnier et al., 2015). In this context, ex vivo priming of MSCs is related to few controversial outcomes in vivo, describing increased immunogenicity of prestimulated MSCs (Papadopoulou et al., 2012; Treacy et al., 2014).

In clinical settings, MSCs from different sources are investigated for the treatment of focal cartilage lesions and OA (Lee and Wang, 2017). Articular
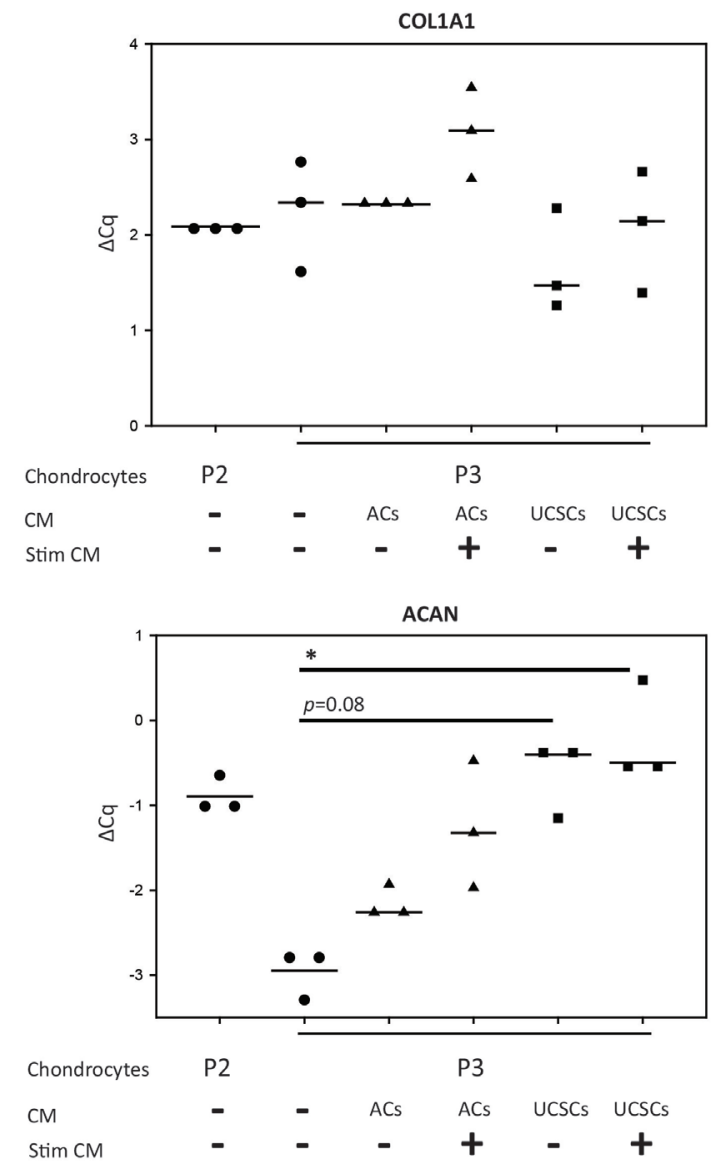

Fig. 10. Effects of UCSCs-CM on cartilage signature gene expression of dedifferentiated chondrocytes in monolayer cultures. Relative expression of COL2A1, COL1A1, SOX9 and ACAN by chondrocytes in the presence of CM from stimulated and non-stimulated ACs and UCSCs. Dedifferentiated chondrocytes at $\mathrm{P} 2$ and $\mathrm{P} 3$ in the absence of $\mathrm{CM}$ were used as controls. $p<0.05 ; n=3$ donors. 
chondrocytes, bone marrow and adipose tissue stromal cells are the most commonly used sources for cartilage repair (Vonk et al., 2015). These studies mostly assess safety and efficacy of used MSCs for specific clinical implications. A comparative study in humans argues that autologous SMSCs exert superior healing outcomes (Akgun et al., 2015). On the other hand, in preclinical models, MSCs from cords exert immunosuppression and disease regression in experimental models of OA and autoimmune disorders (Donders et al., 2015; Saulnier et al., 2015; Yang et al., 2015). In contrast to MSCs from autologous sources, there are only few ongoing trials exploring the potential of allogeneic UCSCs for both OA management and focal cartilage repair in humans (NCT02580695, NCT02291926, NCT03166865 and NCT03358654), without published outcomes hitherto. Confirming the results of the present comparative study in suitable animal models would provide more insight into the use of UCSCs for cartilage disorders in the clinics.

\section{Conclusions}

Traditionally, the regenerative potential of MSCs has been directly linked to their multipotent differentiation and tissue-forming capabilities. Nowadays, increasing attention is given to their role as paracrine modulators. In the field of articular cartilage lesions and degenerative joint diseases, there is no consensus on the best cell source for treatment. Considering the relevance of paracrine signalling, the present study compared the secretome among MSCs from different sources. Both the molecular analyses and the functional assays indicated that UCSCs displayed superior anti-inflammatory and trophic effects when compared to MSCs from adult

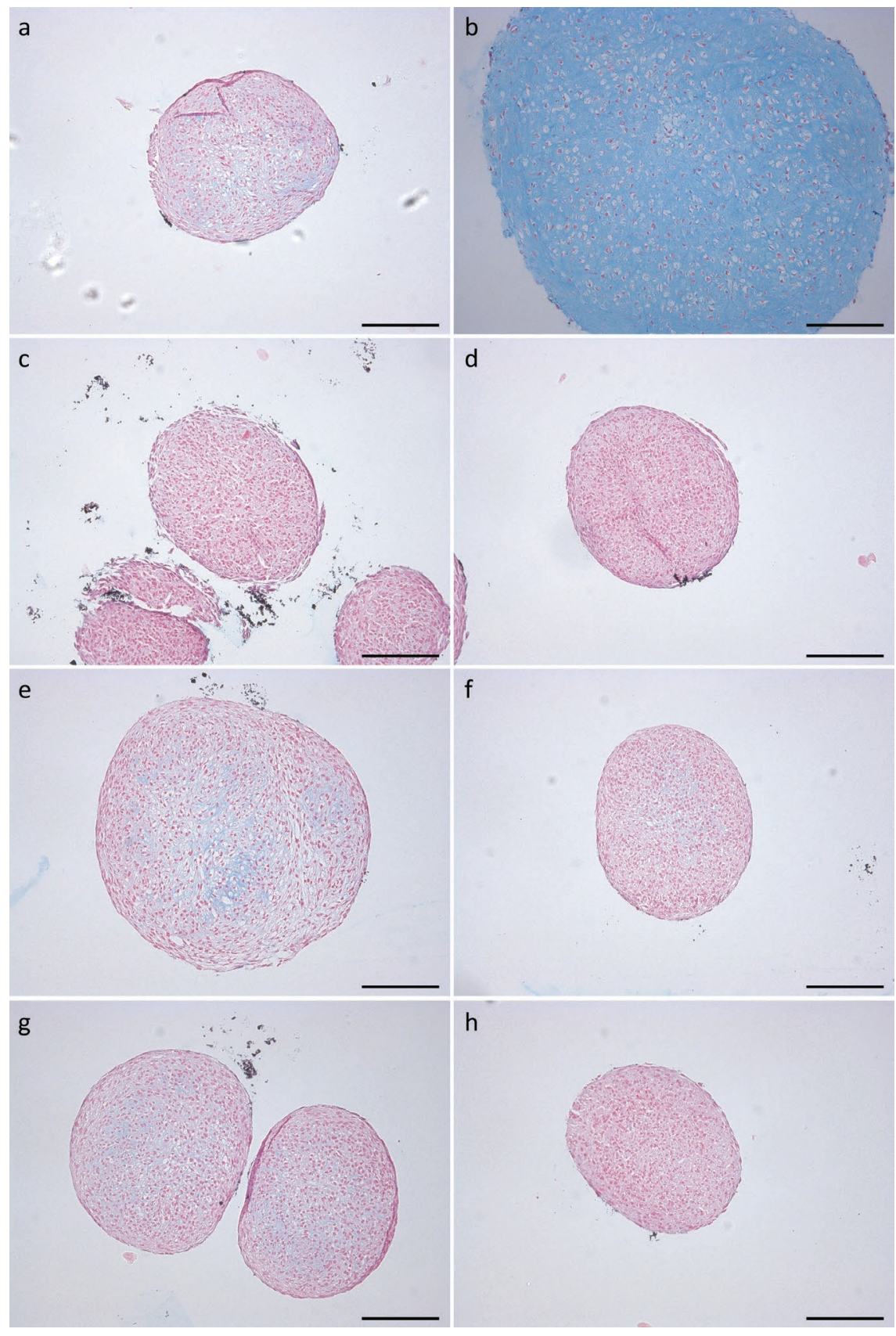

Fig. 11. Effects of CM on in vitro chondrogenesis of dedifferentiated chondrocytes. Spheroids ( $n=2$ donors) were generated by pellet culture method and harvested after $21 \mathrm{~d}$ of chondrogenesis for histological evaluation. Bright light microscopy images of alcian-blue-stained spheroids (4 $\mu$ m-thick sections) show (a) no growth factor, (b) TGF- $\beta 1$ and BMP-2, (c) AC CM, (d) primed AC CM, (e) SMSC CM, (f) primed SMSC CM, (g) UCSC CM and (h) primed UCSC CM. Scale bar: $200 \mu \mathrm{m}$. 
tissues. The hypoimmunogenic nature of UCSCs, along with their high abundance, simple isolation and favourable protein profiles make this cell source an attractive tool for off-the-shelf allogeneic adjuvant therapy.

\section{Acknowledgements}

The authors sincerely thank Dr Geir Tore Abrahamsen and Dr Gunnar Knutsen, University Hospital of Northern Norway (UNN), for providing cartilage and Hoffa's fat pad biopsies, Kirsten Synnøve Nilsen for her assistance with the ELISA assay, Trine Kalstad for her support during Luminex, Dr Ruomei Li for providing reagents for LC-MS/MS, Dr Rodrigo Berzaghi and Kirsti Rønne for their endless support during experiments.

AI primarily conducted the laboratory work, planned the study and prepared the manuscript. IMZ participated in the conception of the study, evaluated the data, edited and approved the final draft of the manuscript. IU and JAB performed the LC-MS/MS. All authors contributed to the data interpretation and provided direction and comments on the manuscript. The datasets used in the study are available upon request to the corresponding author.

This work received financial support from UiT The Arctic University of Norway. The authors declare no competing interests.

\section{References}

Akgun I, Unlu MC, Erdal OA, Ogut T, Erturk M, Ovali E, Kantarci F, Caliskan G, Akgun Y (2015) Matrix-induced autologous mesenchymal stem cell implantation versus matrix-induced autologous chondrocyte implantation in the treatment of chondral defects of the knee: a 2-year randomized study. Arch Orthop Trauma Surg 135: 251-263.

Amable PR, Teixeira MVT, Carias RBV, Granjeiro JM, Borojevic R (2014) Protein synthesis and secretion in human mesenchymal cells derived from bone marrow, adipose tissue and Wharton's jelly. Stem Cell Res Ther 5: 53. DOI: 10.1186/scrt442.

Ambarus CA, Krausz S, van Eijk M, Hamann J, Radstake TR, Reedquist KA, Tak PP, Baeten DL (2012) Systematic validation of specific phenotypic markers for in vitro polarized human macrophages. J Immunol Methods 375: 196-206.

Appleton CT, Usmani SE, Pest MA, Pitelka V, Mort JS, Beier F (2015) Reduction in disease progression by inhibition of transforming growth factor alphaCCL2 signaling in experimental posttraumatic osteoarthritis. Arthritis Rheumatol 67: 2691-2701.

Balasubramanian S, Venugopal P, Sundarraj S, Zakaria Z, Majumdar AS, Ta M (2012) Comparison of chemokine and receptor gene expression between Wharton's jelly and bone marrow-derived mesenchymal stromal cells. Cytotherapy 14: 26-33.
Benderdour M, Tardif G, Pelletier JP, Di Battista JA, Reboul P, Ranger P, Martel-Pelletier J (2002) Interleukin 17 (IL-17) induces collagenase-3 production in human osteoarthritic chondrocytes via AP-1 dependent activation: differential activation of AP-1 members by IL-17 and IL-1beta. J Rheumatol 29: 1262-1272.

Boraldi F, Annovi G, Paolinelli-Devincenzi C, Tiozzo R, Quaglino D (2008) The effect of serum withdrawal on the protein profile of quiescent human dermal fibroblasts in primary cell culture. Proteomics 8: 66-82.

Bouffi C, Bony C, Courties G, Jorgensen C, Noel D (2010) IL-6-dependent PGE2 secretion by mesenchymal stem cells inhibits local inflammation in experimental arthritis. PLoS One 5: e14247. DOI: 10.1371/journal.pone.0014247.

Bouffi C, Bony C, Jorgensen C, Noel D (2011) Skin fibroblasts are potent suppressors of inflammation in experimental arthritis. Ann Rheum Dis 70: 1671-1676.

Caplan AI, Correa D (2011) The MSC: an injury drugstore. Cell Stem Cell 9: 11-15.

Chanteux H, Guisset AC, Pilette C, Sibille Y (2007) LPS induces IL-10 production by human alveolar macrophages via MAPKinases- and Sp1-dependent mechanisms. Respir Res 8: 71. DOI: 10.1186/14659921-8-71.

Chubinskaya S, Haudenschild D, Gasser S, Stannard J, Krettek C, Borrelli J, Jr. (2015) Articular cartilage injury and potential remedies. J Orthop Trauma 29 Suppl 12: S47-52.

Crisan M, Yap S, Casteilla L, Chen CW, Corselli M, Park TS, Andriolo G, Sun B, Zheng B, Zhang L, Norotte C, Teng PN, Traas J, Schugar R, Deasy BM, Badylak S, Buhring HJ, Giacobino JP, Lazzari L, Huard J, Peault B (2008) A perivascular origin for mesenchymal stem cells in multiple human organs. Cell Stem Cell 3: 301-313.

Cross M, Smith E, Hoy D, Nolte S, Ackerman I, Fransen M, Bridgett L, Williams S, Guillemin F, Hill CL, Laslett LL, Jones G, Cicuttini F, Osborne R, Vos T, Buchbinder R, Woolf A, March L (2014) The global burden of hip and knee osteoarthritis: estimates from the global burden of disease 2010 study. Ann Rheum Dis 73: 1323-1330.

Dabrowski FA, Burdzinska A, Kulesza A, Sladowska A, Zolocinska A, Gala K, Paczek L, Wielgos M (2017) Comparison of the paracrine activity of mesenchymal stem cells derived from human umbilical cord, amniotic membrane and adipose tissue. J Obstet Gynaecol Res 43: 1758-1768.

de Hooge AS, van de Loo FA, Bennink MB, Arntz OJ, de Hooge P, van den Berg WB (2005) Male IL-6 gene knock out mice developed more advanced osteoarthritis upon aging. Osteoarthritis Cartilage 13: 66-73.

de Windt TS, Vonk LA, Slaper-Cortenbach ICM, Nizak R, van Rijen MHP, Saris DBF (2017) Allogeneic MSCs and recycled autologous chondrons mixed in a one-stage cartilage cell transplantion: a first-in-man trial in 35 patients. Stem Cells 35: 1984-1993. 
Dell'Accio F, Vanlauwe J, Bellemans J, Neys J, De Bari C, Luyten FP (2003) Expanded phenotypically stable chondrocytes persist in the repair tissue and contribute to cartilage matrix formation and structural integration in a goat model of autologous chondrocyte implantation. J Orthop Res 21: 123-131.

Donders R, Bogie JFJ, Ravanidis S, Gervois $P$, Vanheusden $M$, Maree R, Schrynemackers $M$, Smeets HJM, Pinxteren J, Gijbels K, Walbers S, Mays RW, Deans R, Van Den Bosch L, Stinissen P, Lambrichts I, Gyselaers W, Hellings N (2018) Human Wharton's jelly-derived stem cells display a distinct immunomodulatory and proregenerative transcriptional signature compared to bone marrowderived stem cells. Stem Cells Dev 27: 65-84.

Donders R, Vanheusden M, Bogie JF, Ravanidis S, Thewissen K, Stinissen P, Gyselaers W, Hendriks JJ, Hellings N (2015) Human Wharton's jelly-derived stem cells display immunomodulatory properties and transiently improve rat experimental autoimmune encephalomyelitis. Cell Transplant 24: 2077-2098.

Garcia J, Mennan C, McCarthy HS, Roberts S, Richardson JB, Wright KT (2016) Chondrogenic potency analyses of donor-matched chondrocytes and mesenchymal stem cells derived from bone marrow, infrapatellar fat pad, and subcutaneous fat. Stem Cells Int 2016: 6969726. DOI: 10.1155/2016/6969726.

Ghannam S, Bouffi C, Djouad F, Jorgensen C, Noel D (2010) Immunosuppression by mesenchymal stem cells: mechanisms and clinical applications. Stem Cell Res Ther 1: 2. DOI: 10.1186/scrt2.

Gnecchi M, Danieli P, Malpasso G, Ciuffreda MC (2016) Paracrine mechanisms of mesenchymal stem cells in tissue repair. Methods Mol Biol 1416: 123-146.

Gomez-Aristizabal A, Sharma A, Bakooshli MA, Kapoor M, Gilbert PM, Viswanathan S, Gandhi R (2017) Stage-specific differences in secretory profile of mesenchymal stromal cells (MSCs) subjected to early- vs late-stage OA synovial fluid. Osteoarthritis Cartilage 25: 737-741.

Gorchs L, Hellevik T, Bruun J-A, Camilio K-A, Al-Saad S, Stuge T-B, Martinez-Zubiaurre I (2015) Cancer-associated fibroblasts from lung tumors maintain their immunosuppressive abilities after high-dose irradiation. Front Oncol 5: 87-87.

Grande DA, Pitman MI, Peterson L, Menche D, Klein M (1989) The repair of experimentally produced defects in rabbit articular cartilage by autologous chondrocyte transplantation. J Orthop Res 7: 208-218.

Guimaraes-Camboa N, Cattaneo P, Sun Y, MooreMorris T, Gu Y, Dalton ND, Rockenstein E, Masliah E, Peterson KL, Stallcup WB, Chen J, Evans SM (2017) Pericytes of multiple organs do not behave as mesenchymal stem cells in vivo. Cell Stem Cell 20: 345-359.e5.

Hansen AK, Figenschau Y, Zubiaurre-Martinez I (2017) Co-expression of $1 \alpha$-hydroxylase and vitamin $\mathrm{D}$ receptor in human articular chondrocytes. BMC Musculoskeletal Disorders 18: 432. DOI: 10.1186/ s12891-017-1791-y.
Heo JS, Choi Y, Kim HS, Kim HO (2016) Comparison of molecular profiles of human mesenchymal stem cells derived from bone marrow, umbilical cord blood, placenta and adipose tissue. Int J Mol Med 37: 115-125.

Hsiao ST, Asgari A, Lokmic Z, Sinclair R, Dusting GJ, Lim SY, Dilley RJ (2012) Comparative analysis of paracrine factor expression in human adult mesenchymal stem cells derived from bone marrow, adipose, and dermal tissue. Stem Cells Dev 21: 21892203.

Islam A, Fossum V, Hansen AK, Urbarova I, Knutsen G, Martinez-Zubiaurre I (2019) In vitro chondrogenic potency of surplus chondrocytes from autologous transplantation procedures does not predict short-term clinical outcomes. BMC Musculoskelet Disord 20: 19. DOI: 10.1186/s12891018-2380-4.

Islam A, Hansen AK, Mennan C, MartinezZubiaurre I (2016) Mesenchymal stromal cells from human umbilical cords display poor chondrogenic potential in scaffold-free three dimensional cultures. Eur Cell Mater 31: 407-424.

Islam A, Romijn EI, Lilledahl MB, MartinezZubiaurre I (2017) Non-linear optical microscopy as a novel quantitative and label-free imaging modality to improve the assessment of tissue-engineered cartilage. Osteoarthritis Cartilage 25: 1729-1737.

Iso Y, Spees JL, Serrano C, Bakondi B, Pochampally $\mathrm{R}$, Song YH, Sobel BE, Delafontaine P, Prockop DJ (2007) Multipotent human stromal cells improve cardiac function after myocardial infarction in mice without long-term engraftment. Biochem Biophys Res Commun 354: 700-706.

Jaguin M, Houlbert N, Fardel O, Lecureur V (2013) Polarization profiles of human M-CSF-generated macrophages and comparison of M1-markers in classically activated macrophages from GM-CSF and M-CSF origin. Cell Immunol 281: 51-61.

Jin HJ, Bae YK, Kim M, Kwon SJ, Jeon HB, Choi SJ, Kim SW, Yang YS, Oh W, Chang JW (2013) Comparative analysis of human mesenchymal stem cells from bone marrow, adipose tissue, and umbilical cord blood as sources of cell therapy. Int J Mol Sci 14: 17986-18001.

Karaoz E, Cetinalp Demircan P, Erman G, Gungorurler E, Eker Sariboyaci A (2017) Comparative analyses of immunosuppressive characteristics of bone-marrow, Wharton's jelly, and adipose tissuederived human mesenchymal stem cells. Turk J Haematol 34: 213-225.

Knutsen G, Drogset JO, Engebretsen L, Grontvedt T, Ludvigsen TC, Loken S, Solheim E, Strand T, Johansen O (2016) A Randomized multicenter trial comparing autologous chondrocyte implantation with microfracture: long-term follow-up at 14 to 15 years. J Bone Joint Surg Am 98: 1332-1339.

Kondo M, Yamaoka K, Sonomoto K, Fukuyo S, Oshita K, Okada Y, Tanaka Y (2013) IL-17 inhibits chondrogenic differentiation of human mesenchymal 
stem cells. PLoS One 8: e79463. DOI: 10.1371/journal. pone.0079463.

Lee WY-w, Wang B (2017) Cartilage repair by mesenchymal stem cells: clinical trial update and perspectives. J Orthop Translat 9: 76-88.

Li CY, Wu XY, Tong JB, Yang XX, Zhao JL, Zheng QF, Zhao GB, Ma ZJ (2015) Comparative analysis of human mesenchymal stem cells from bone marrow and adipose tissue under xeno-free conditions for cell therapy. Stem Cell Res Ther 6: 55. DOI: 10.1186/ s13287-015-0066-5.

Liechty KW, MacKenzie TC, Shaaban AF, Radu A, Moseley AM, Deans R, Marshak DR, Flake AW (2000) Human mesenchymal stem cells engraft and demonstrate site-specific differentiation after in utero transplantation in sheep. Nat Med 6: 1282-1286.

Lohan P, Treacy O, Lynch K, Barry F, Murphy M, Griffin MD, Ritter T, Ryan AE (2016) Culture expanded primary chondrocytes have potent immunomodulatory properties and do not induce an allogeneic immune response. Osteoarthritis Cartilage 24: 521-533.

Manferdini C, Paolella F, Gabusi E, Gambari L, Piacentini A, Filardo G, Fleury-Cappellesso S, Barbero A, Murphy M, Lisignoli G (2017) Adipose stromal cells mediated switching of the pro-inflammatory profile of M1-like macrophages is facilitated by PGE2: in vitro evaluation. Osteoarthritis Cartilage 25: 11611171.

Miwa M, Saura R, Hirata S, Hayashi Y, Mizuno $\mathrm{K}$, Itoh H (2000) Induction of apoptosis in bovine articular chondrocyte by prostaglandin E(2) through cAMP-dependent pathway. Osteoarthritis Cartilage 8: 17-24.

Muthuri SG, McWilliams DF, Doherty M, Zhang W (2011) History of knee injuries and knee osteoarthritis: a meta-analysis of observational studies. Osteoarthritis Cartilage 19: 1286-1293.

Najar M, Raicevic G, Kazan HF, De Bruyn C, Bron D, Toungouz M, Lagneaux L (2012) Immune-related antigens, surface molecules and regulatory factors in human-derived mesenchymal stromal cells: the expression and impact of inflammatory priming. Stem Cell Rev 8: 1188-1198.

Ogura T, Bryant T, Minas T (2017) Long-term outcomes of autologous chondrocyte implantation in adolescent patients. Am J Sports Med 45: 1066-1074.

Otsuka S, Aoyama T, Furu M, Ito K, Jin Y, Nasu A, Fukiage K, Kohno Y, Maruyama T, Kanaji T, Nishiura A, Sugihara H, Fujimura S, Otsuka T, Nakamura T, Toguchida J (2009) PGE2 signal via EP2 receptors evoked by a selective agonist enhances regeneration of injured articular cartilage. Osteoarthritis Cartilage 17: 529-538.

Ozeki N, Muneta T, Koga H, Nakagawa Y, Mizuno M, Tsuji K, Mabuchi Y, Akazawa C, Kobayashi E, Matsumoto K, Futamura K, Saito T, Sekiya I (2016) Not single but periodic injections of synovial mesenchymal stem cells maintain viable cells in knees and inhibit osteoarthritis progression in rats. Osteoarthritis Cartilage 24: 1061-1070.
Papadopoulou A, Yiangou M, Athanasiou E, Zogas N, Kaloyannidis P, Batsis I, Fassas A, Anagnostopoulos A, Yannaki E (2012) Mesenchymal stem cells are conditionally therapeutic in preclinical models of rheumatoid arthritis. Ann Rheum Dis 71: 1733-1740.

Patel VJ, Thalassinos K, Slade SE, Connolly JB, Crombie A, Murrell JC, Scrivens JH (2009) A comparison of labeling and label-free mass spectrometry-based proteomics approaches. J Proteome Res 8: 3752-3759.

Pazos F, Chagoyen M (2009) Quantifying the biological significance of gene ontology biological processes - implications for the analysis of systemswide data. Bioinformatics 26: 378-384.

Peeters CM, Leijs MJ, Reijman M, van Osch GJ, Bos PK (2013) Safety of intra-articular cell-therapy with culture-expanded stem cells in humans: a systematic literature review. Osteoarthritis Cartilage 21: 14651473.

Poree B, Kypriotou M, Chadjichristos C, Beauchef G, Renard E, Legendre F, Melin M, Gueret S, Hartmann DJ, Mallein-Gerin F, Pujol JP, Boumediene K, Galera P (2008) Interleukin-6 (IL-6) and/or soluble IL-6 receptor down-regulation of human type II collagen gene expression in articular chondrocytes requires a decrease of Sp1.Sp3 ratio and of the binding activity of both factors to the COL2A1 promoter. J Biol Chem 283: 4850-4865.

Prockop DJ (2009) Repair of tissues by adult stem/ progenitor cells (MSCs): controversies, myths, and changing paradigms. Mol Ther 17: 939-946.

Rehman J, Traktuev D, Li J, Merfeld-Clauss S, Temm-Grove CJ, Bovenkerk JE, Pell CL, Johnstone BH, Considine RV, March KL (2004) Secretion of angiogenic and antiapoptotic factors by human adipose stromal cells. Circulation 109: 1292-1298.

Saris D, Price A, Widuchowski W, BertrandMarchand M, Caron J, Drogset JO, Emans P, Podskubka A, Tsuchida A, Kili S, Levine D, Brittberg M (2014) Matrix-applied characterized autologous cultured chondrocytes versus microfracture:two-year follow-up of a prospective randomized trial. Am J Sports Med 42: 1384-1394.

Sato K, Kondo M, Sakuta K, Hosoi A, Noji S, Sugiura M, Yoshida Y, Kakimi K (2009) Impact of culture medium on the expansion of $\mathrm{T}$ cells for immunotherapy. Cytotherapy 11: 936-946.

Saulnier N, Viguier E, Perrier-Groult E, Chenu C, Pillet E, Roger T, Maddens S, Boulocher C (2015) Intra-articular administration of xenogeneic neonatal mesenchymal stromal cells early after meniscal injury down-regulates metalloproteinase gene expression in synovium and prevents cartilage degradation in a rabbit model of osteoarthritis. Osteoarthritis Cartilage 23: 122-133.

Singh A, Goel SC, Gupta KK, Kumar M, Arun GR, Patil H, Kumaraswamy V, Jha S (2014) The role of stem cells in osteoarthritis: an experimental study in rabbits. Bone Joint Res 3: 32-37. 
Snelling SJ, Bas S, Puskas GJ, Dakin SG, Suva D, Finckh A, Gabay C, Hoffmeyer P, Carr AJ, Lubbeke A (2017) Presence of IL-17 in synovial fluid identifies a potential inflammatory osteoarthritic phenotype. PLoS One 12: e0175109. DOI: 10.1371/journal. pone.0175109.

Subramanian A, Fong CY, Biswas A, Bongso A (2015) Comparative characterization of cells from the various compartments of the human umbilical cord shows that the Wharton's jelly compartment provides the best source of clinically utilizable mesenchymal stem cells. PLoS One 10: e0127992. DOI: 10.1371/ journal.pone.0127992

Sui Y, Lee JH, DiMicco MA, Vanderploeg EJ, Blake SM, Hung HH, Plaas AH, James IE, Song XY, Lark MW, Grodzinsky AJ (2009) Mechanical injury potentiates proteoglycan catabolism induced by interleukin- 6 with soluble interleukin- 6 receptor and tumor necrosis factor alpha in immature bovine and adult human articular cartilage. Arthritis Rheum 60: 2985-2996.

Tang X, Fan L, Pei M, Zeng L, Ge Z (2015) Evolving concepts of chondrogenic differentiation: history, state-of-the-art and future perspectives. Eur Cell Mater 30: 12-27.

Treacy O, O'Flynn L, Ryan AE, Morcos M, Lohan P, Schu S, Wilk M, Fahy G, Griffin MD, Nosov M, Ritter T (2014) Mesenchymal stem cell therapy promotes corneal allograft survival in rats by local and systemic immunomodulation. Am J Transplant 14: 2023-2036.

van Buul GM, Villafuertes E, Bos PK, Waarsing JH, Kops N, Narcisi R, Weinans H, Verhaar JA, Bernsen MR, van Osch GJ (2012) Mesenchymal stem cells secrete factors that inhibit inflammatory processes in short-term osteoarthritic synovium and cartilage explant culture. Osteoarthritis Cartilage 20: 11861196.

van den Borne MPJ, Raijmakers NJH, Vanlauwe J, Victor J, de Jong SN, Bellemans J, Saris DBF (2007) International Cartilage Repair Society (ICRS) and oswestry macroscopic cartilage evaluation scores validated for use in autologous chondrocyte implantation (ACI) and microfracture. Osteoarthritis Cartilage 15: 1397-1402.

Vizcaíno JA, Csordas A, del-Toro N, Dianes JA, Griss J, Lavidas I, Mayer G, Perez-Riverol Y, Reisinger F, Ternent T, Xu Q-W, Wang R, Hermjakob H (2016) 2016 update of the PRIDE database and its related tools. Nucleic Acids Research 44: D447-D456.

Vogel DY, Glim JE, Stavenuiter AW, Breur M, Heijnen P, Amor S, Dijkstra CD, Beelen RH (2014) Human macrophage polarization in vitro: maturation and activation methods compared. Immunobiology 219: 695-703.

von Bahr L, Sundberg B, Lonnies L, Sander B, Karbach H, Hagglund H, Ljungman P, Gustafsson B, Karlsson H, Le Blanc K, Ringden O (2012) Longterm complications, immunologic effects, and role of passage for outcome in mesenchymal stromal cell therapy. Biol Blood Marrow Transplant 18: 557-564.
Vonk LA, de Windt TS, Slaper-Cortenbach IC, Saris DB (2015) Autologous, allogeneic, induced pluripotent stem cell or a combination stem cell therapy? Where are we headed in cartilage repair and why: a concise review. Stem Cell Res Ther 6: 94. DOI: 10.1186/s13287-015-0086-1.

Wang Z, Zheng C, Zhong Y, He J, Cao X, Xia H, Ba H, Li P, Wu S, Peng C (2017) Interleukin-17 can induce osteoarthritis in rabbit knee joints similar to Hulth's method. Biomed Res Int 2017: 2091325. DOI: 10.1155/2017/2091325

Wei J, Sun Z, Chen Q, Gu J (2006) Serum deprivation induced apoptosis in macrophage is mediated by autocrine secretion of type I IFNs. Apoptosis 11: 545-554.

Wolfstadt JI, Cole BJ, Ogilvie-Harris DJ, Viswanathan S, Chahal J (2015) Current concepts: the role of mesenchymal stem cells in the management of knee osteoarthritis. Sports Health 7: 38-44.

$\mathrm{Xu}$ YK, Ke Y, Wang B, Lin JH (2015) The role of MCP-1-CCR2 ligand-receptor axis in chondrocyte degradation and disease progress in knee osteoarthritis. Biol Res 48: 64. DOI 10.1186/ s40659-015-0057-0.

Yang X, Zhu TY, Wen LC, Cao YP, Liu C, Cui YP, Meng ZC, Liu H (2015) Intraarticular injection of allogenic mesenchymal stem cells has a protective role for the osteoarthritis. Chin Med J (Engl) 128: 2516-2523.

Zhang P, Zhong ZH, Yu HT, Liu B (2015) Exogenous expression of IL-1Ra and TGF-beta1 promotes in vivo repair in experimental rabbit osteoarthritis. Scand J Rheumatol 44: 404-411.

Zhao XY, Yang ZB, Zhang ZJ, Zhang ZQ, Kang Y, Huang GX, Wang SW, Huang H, Liao WM (2015) CCL3 serves as a potential plasma biomarker in knee degeneration (osteoarthritis). Osteoarthritis Cartilage 23: $1405-1411$.

Zhen G, Wen C, Jia X, Li Y, Crane JL, Mears SC, Askin FB, Frassica FJ, Chang W, Yao J, Carrino JA, Cosgarea A, Artemov D, Chen Q, Zhao Z, Zhou X, Riley L, Sponseller P, Wan M, Lu WW, Cao X (2013) Inhibition of TGF- $\beta$ signaling in mesenchymal stem cells of subchondral bone attenuates osteoarthritis. Nature Medicine 19: 704-712.

\section{Web References}

1. https://www.uniprot.org/proteomes/ UP000005640 [19-02-2019]

\section{Discussion with Reviewers}

Andrea Barbero: The authors have analysed the secretome of different MSCs after their in vitro culture. However, the secretion profile of cells can drastically change after their injection in the joint (i.e. an environment that is extremely more complex that 
the in vitro one). Can the authors state their opinion on this issue?

Authors: We agree with the reviewer on the likelihood of cells displaying different secretome in vitro and in joint conditions. Unfortunately, the technology to assess the secretory profile of the implanted MSCs in vivo was not available. To shed some light on this point, cells were stimulated in vitro with a cocktail of inflammatory cytokines. Results showed that adult MSCs became more immunosuppressive in inflammatory environments. This point has also been discussed in the manuscript.

Lucienne Vonk: For future purposes, how do you envision to produce a well-characterised and qualitycontrolled product from the secretome of stromal cells?

Authors: To produce a well-characterised and quality-controlled product from the secretome of stromal cells is almost as complicated as to produce a quality-controlled and well-characterised product from stromal cells per se. As shown in the proteomic analyses, secretomes from stromal cells contained (at least) more than 500 different proteins and it was difficult to speculate which individual factor or cocktail of factors might play a role in inflammation or tissue repair. Most probably different paracrine signal molecules act concomitantly. A well-characterised product would require knowing exactly which molecules are present in the product and what would be the precise effect of those bioactive factors. Actions that could help to move in that direction would include characterisation of samples by fractionation (for example molecular size). Specific blockade of distinct factors would also help to ascertain which factors from the entire secretome are more relevant to induce repair. One possibility is that the effects of $\mathrm{CM}$ would come from the extracellular vesicles. In this case, the complexity of the sample preparation would be reduced. Still, a well-characterised product would require a thorough characterisation of the extracellular vesicles and the determination of the effector molecule(s) which could include miRNA or other non-protein molecules. Most probably the effects from stromal cells secretome are multifactorial and not reduced to one or a handful of factors, so that the manufacture of a well-characterised and qualitycontrolled product for its safe use in clinics is close to an oxymoron.
Yuk Wai Lee: How did the authors ensure they were detecting secretory cytokines but not residual cytokines from the serum or cytokines released from the cells due to cell damage/death?

Authors: Residual amounts of serum proteins could be present in the experimental samples. However, after extensive washings, only very abundant serum proteins, such as albumin or immunoglobulins, can be detected by MS. In any case, this aspect would be equal for all experimental samples and would not have an impact on the outcomes of the study, which focussed on differences between experimental groups. The same argument applied to proteins derived from dead cells. Notably, the extent of cell death in cultures at the time of supernatants collection (from all cell sources) was negligible/undetectable by trypan blue exclusion.

Katie Lee: Why did the authors choose to culture the cells in normoxic conditions, rather than more physiologically relevant hypoxic conditions?

Authors: It could be interesting to check hypoxic culture conditions. Surface markers characterisation of MSCs is routinely performed by the authors, showing no significant differences in surface markers expression during monolayer culture in high or low oxygen tensions. In our experience, hypoxic environments play a more important role in 3D cultures and chondrogenesis. Therefore, normoxic conditions were used in the study.

Katie Lee: How did the authors confirm the cell types isolated in the study were actually MSCs and not fibroblasts or other forms of progenitor cell?

Authors: MSCs were referred to as mesenchymal stromal cells (not stem cells), emphasising on the stromal origin more than the stem cell or progenitor nature. This was consciously done taking into consideration that it is very difficult to differentiate between progenitor cells, fibroblasts or other type of stromal cells based on phenotypic markers or even on their multi-differentiation. By using the term mesenchymal stromal cells, the potential problem with semantics was circumvented.

Editor's note: The Scientific Editor responsible for this paper was Christine Hartmann. 